\title{
Exploring Jasmonates in the Hormonal Network of Drought and Salinity Responses
}

\author{
Michael Riemann ${ }^{1}$, Rohit Dhakarey ${ }^{1}$, Mohamed Hazman ${ }^{1}$, Berta Miro ${ }^{2}$, Ajay Kohli ${ }^{2 *}$ and \\ Peter Nick ${ }^{1 *}$ \\ ${ }^{1}$ Molecular Cell Biology, Institute of Botany, Karlsruhe Institute of Technology, Karlsruhe, Germany, ${ }^{2}$ Plant Breeding Genetics \\ and Biotechnology Division, International Rice Research Institute, Makati, Philippines
}

OPEN ACCESS

Edited by:

Girdhar K. Pandey,

University of Delhi, India

Reviewed by:

Rajeev K. Varshney,

International Crops Research Institute for the Semi-Arid Tropics, India

Iwona M. Morkunas,

Poznań University of Life Sciences,

Poland

Manoj Prasad,

National Institute of Plant Genome

Research, India

*Correspondence:

Peter Nick

peter.nick@kit.edu

Ajay Kohli

a.kohli@irri.org

Specialty section: This article was submitted to Plant Physiology,

a section of the journal

Frontiers in Plant Science

Received: 19 July 2015 Accepted: 17 November 2015 Published: 01 December 2015

Citation:

Riemann M, Dhakarey R, Hazman M, Miro B, Kohli A and Nick P (2015)

Exploring Jasmonates

in the Hormonal Network of Drought

and Salinity Responses.

Front. Plant Sci. 6:1077.

doi: 10.3389/fp/s.2015.01077
Present and future food security is a critical issue compounded by the consequences of climate change on agriculture. Stress perception and signal transduction in plants causes changes in gene or protein expression which lead to metabolic and physiological responses. Phytohormones play a central role in the integration of different upstream signals into different adaptive outputs such as changes in the activity of ion-channels, protein modifications, protein degradation, and gene expression. Phytohormone biosynthesis and signaling, and recently also phytohormone crosstalk have been investigated intensively, but the function of jasmonates under abiotic stress is still only partially understood. Although most aspects of jasmonate biosynthesis, crosstalk and signal transduction appear to be similar for biotic and abiotic stress, novel aspects have emerged that seem to be unique for the abiotic stress response. Here, we review the knowledge on the role of jasmonates under drought and salinity. The crosstalk of jasmonate biosynthesis and signal transduction pathways with those of abscisic acid (ABA) is particularly taken into account due to the well-established, central role of ABA under abiotic stress. Likewise, the accumulating evidence of crosstalk of jasmonate signaling with other phytohormones is considered as important element of an integrated phytohormonal response. Finally, protein post-translational modification, which can also occur without de novo transcription, is treated with respect to its implications for phytohormone biosynthesis, signaling and crosstalk. To breed climateresilient crop varieties, integrated understanding of the molecular processes is required to modulate and tailor particular nodes of the network to positively affect stress tolerance.

Keywords: phytohormones, jasmonic acid, abscisic acid, abiotic stress, drought, salinity

\section{INTRODUCTION}

During the last century, the Green Revolution led to food security for a rapidly growing global population through an impressive growth of productivity achieved by mineral fertilizers, chemical plant protection, and mechanization. However, the central factor driving the yield increase was genetics. For instance, the reduction of culm length by mutations in DELLA gibberellin-response factors (Peng et al., 1999) substantially reduced losses by lodging that, in rice, can reach up to 40\% (Nishiyama, 1986). Although there is still potential for further increases in crop yield, it has also become clear that plant science of the new century must address additional targets: The land 
amenable to agriculture is limited and crop production is further constrained by land use for biofuels, urbanization, and desertification. The situation is further accentuated by unpredictable patterns of climate change. The case of desperate farmers who, in expectation of high yields, spend their funds for seeds of high-yielding improved cultivars, and then witness crop failure due to altered rain, temperature and light regimes illustrates that crop breeding must integrate additional traits in addition to improved photosynthetic efficiency or optimal partitioning of assimilates to the culm, for example. Altered regimes of abiotic factors lead to alterations in biotic stress factors as a corollary. Crop resilience to biotic and abiotic stress conditions has therefore shifted into the focus of plant research worldwide (for review, see Passioura, 2002). During evolution, the immobile nature of plants has forced them to evolve unique and sophisticated mechanisms to tolerate abiotic stress. The natural variation in those mechanisms can be used to develop more tolerant crop plants. As prerequisite, we have to understand the underlying molecular, biochemical, and physiological aspects of stress tolerance.

Among the abiotic stress factors, the varied osmotic challenges posed by drought, salinity, and alkalinity together account for maximal yield losses in major crops. Water scarcity is probably the most serious constraint for crop quality and productivity among all environmental factors, compromising economic output and human food supply (Roche et al., 2009). Just salinity alone affects approximately $20 \%$ of the irrigated lands of the world. In addition, every year a large fraction of agricultural land is oversalted and becomes unusable (Yeo, 1999; Williams, 2001). The costs to agriculture caused by salinity are huge and are expected to increase as further regions are contaminated with salt (Ghassemi et al., 1995). For instance, deposition of toxic salt sediments and sea intrusion in tsunami-affected areas of the Maldives damaged $70 \%$ of agriculture land, destroyed some 370,000 fruit trees, and affected around 15,000 farmers, with estimated costs at around AU\$ 6.5 million (FAO, 2005). Unfortunately, salinity is a manmade problem to some extent, caused by agricultural practices such as land clearing and the replacement of perennial vegetation with annual crops and irrigation schemes using salt-rich irrigation water or having insufficient drainage (Munns, 2002). The impact of drought in terms of yield, economy and negative effect on society is even more substantial (Kantar et al., 2011). An FAO report estimated that drought wrought irrevocable negative implications on two billion and killed 11 million people during the last century, more than any other hydro-meteorological hazard (FAO, 2013).

Although in general perceived as mere water scarcity, osmotic stress in reality represents a complex syndrome comprising at least three components that can occur either individually or in different combinations: water scarcity stress (drought), ionic stress (salinity), and nutrient-depletion stress (alkalinity). Adaptation to the three osmotic stresses requires cellular and physiological responses that must be at least partially different depending on the dominating stress component. For instance, drought can primarily affect cell turgidity causing growth arrest and stomatal closure, resulting in photosynthetic imbalance, and impaired redox homeostasis. Salinity can, in addition, impair ionic homeostasis. Thus, adaptation to salinity not only has to reinstall turgidity, but also has to reinstall the equilibrium between important ions such as sodium and potassium. Specific adaptive responses must be triggered by specific signaling cascades as well, involving specific molecular components. However, the number of molecular players that convey stress signals in plants is rather limited and many of these molecular players are shared between different stresses (Ismail et al., 2014b). One model to explain this specificity achieved by a limited set of mostly common factors conceptualizes particular spatiotemporal patterns (so called signatures) of these overlapping signals and the signaling pathways (Ismail et al., 2014b).

A proof of concept for this signatures model, is provided by stress induced calcium patterns. By means of aequorin-reporter plants, different stress factors were shown to produce different temporal signatures of calcium (Knight et al., 1991, reviewed in McAinsh and Hetherington, 1998). The fact that signatures differ between different stresses, does not prove per se that these signatures are causative for signal specificity. A functional proof requires manipulating the signatures, which is far from trivial. In case of calcium, this was successfully achieved in guard cells by rhythmic incubations with calcium-containing and calciumfree buffers, and this artificial calcium signature allowed rescuing the deficient stomatal closure in the det 3 mutant of Arabidopsis (Allen et al., 2000). Similar signatures seem to act also for other stress signals. For instance, the specificity of reactive oxygen species (ROS) as signals in the processing of drought and salinity stress seems to depend on their subcellular distribution (reviewed in Miller et al., 2010). Likewise, the interaction of jasmonate signaling with other signal chains converging at the proteasome can generate specific outputs (reviewed in Kazan and Manners, 2008). As common theme in these examples, the specificity of signaling seems to stem from specific combinations of fairly general primary signals. For instance, while drought, salt, and cold stress will all activate calcium influx, the "physiological meaning" of this influx is modulated by different, stress-quality specific second messengers to yield different responses (Xiong et al., 2002). This combinatorial model predicts that there exists something like a "grammar of stress signaling," and when we want to understand, how plants can discriminate the three components of osmotic stress and even specific combinations of them, we have to decipher this "grammar" in the first place.

As a proof of concept, temporal signatures have been dissected for salinity stress in grapevine cells (reviewed Ismail et al., 2014b). Input is either through a (mechanosensitive) calcium influx channel at the membrane, which often acts in concert through the membrane-located NADPH-oxidase Respiratory burst oxidase Homolog $(\mathrm{RboH})$, generating apoplastic ROS. Transduction is conveyed by calcium-binding proteins (CDPKs, calcineurins), a MAP-Kinase cascade, and jasmonates [oxophytodienoic acid (OPDA), jasmonic acid (JA), JA-Isoleucine conjugate (JA-Ile), methyl jasmonate (MeJA)]. Depending on the relative temporal patterns of these upstream signals, the cellular responses were qualitatively different. In one case adaptive responses such as activation of enzymatic antioxidants, osmoprotectants or ion channels resulted in cellular adaptation, whereas in the other case, temporal shifts of early signaling events culminated in necrotic 
death, which for a cell is a fatal outcome, but for a plant may be adaptive, because it provides a strategy to exclude noxious salt by abscission of a leaf that is thus sacrificed for the sake of the entire plant.

The synthesis, modification, and signaling of jasmonates has been reviewed comprehensively by Wasternack and Hause (2013), and these authors have also extensively treated the role of this pathway for the plant responses to different stress factors. The current review will therefore focus on the role of temporal jasmonate signatures for the adaptive response to osmotic challenges (drought and salinity stress). We address possible mechanisms ensuring specificity for these partially similar stress conditions that on the other hand require partially different responses. In particular, we show that dynamic feedback of jasmonate signaling upon jasmonate synthesis along with different ramifications in synthesis and modification of JA are relevant to constrain this potentially dangerous stress signal in a manner that is tuned with activation of other pathways, prominently abscisic acid (ABA) signaling.

\section{THE PRIMARY CAUSE FOR SPECIFICITY MUST BE SEARCHED IN DIFFERENT CHANNELS OF PERCEPTION}

Modulations in the phytohormonal levels and signaling status in response to abiotic stress have been intensively studied for decades, with often contradictive results, where upregulation of a given hormone was found to confer stress adaptation in one case, but was found to impair survival in a different case. These discrepancies show already that phytohormones apparently do not act as early transducers of stress signals, but rather seem to act as integrators of different upstream signals. Therefore, before we will deal jasmonates themselves, it is important to have a look on these upstream signals.

The actual input for drought stress signaling is certainly mechanical load of the membrane. The osmotically caused loss of turgidity will affect membrane tension, and this can be perceived through changes in the activity of mechanosensitive ion channels, a mechanism that was developed early in evolution and functions already in prokaryotic cells (reviewed in Kung, 2005). In plant cells, such mechanosensitive channels drive an influx of calcium. Contrarily, the calcium output caused by mechanical challenge of the membrane is also used to perceive a range of stress factors different from osmotic stress such as touch, gravity, wounding, or cold (reviewed in Nick, 2011). The molecular nature of these channels has remained elusive for decades. The recent discovery of the calcium channel OSCA1 from Arabidopsis thaliana that is gated by hyperosmotic stress (Yuan et al., 2014) might mean that a central player for the perception of osmotic challenge of the membrane has been identified. The influx of calcium can be transduced through calcium dependent kinases into activation of the NADPH oxidase RboH generating apoplastic singlet oxygen, such that calcium influx is followed (with some delay) by a transient oxidative burst (Dubiella et al., 2013). At the cellular level, adaptation is brought about by production of compatible osmolytes that will help to reinstall turgidity. Also, a well-known response is the synthesis of late-embryogenesis abundant (LEA) proteins that will prevent protein precipitation (Tunnacliffe and Wise, 2007). At the organismal level, rapid closure of stomata will reduce additional loss of water (for review Xoconostle-Cázares et al., 2011).

For salinity stress, the osmotically induced $\mathrm{Ca}$ influx is accompanied by a second factor, ionic stress. In fact, sodium ions can pass the plasma membrane by non-selective cation channels (NSCCs). A comparison of two grapevine cell lines that differ in salt tolerance revealed that efficient adaptation correlated with a more rapid uptake of sodium into the cytoplasm indicating that the concomitant increase of cytosolic calcium and sodium might act as a signal triggering salinity adaptation (Ismail et al., 2014a). The adaptive salt overly sensitive (SOS) module cannot only extrude sodium from the cytoplasm, but also links cytosolic sodium with calcium signaling (reviewed in Ismail et al., 2014b). Although some of the adaptive responses to salinity are shared with drought stress (reviewed in Hasegawa et al., 2000), such as induction of osmolytes, accumulation of LEA proteins, or stomatal closure, others are specific for salinity. For instance, sodium can be extruded by the SOS1 exporter (Munns and Tester, 2008), or it can be sequestered into the vacuole through the NHX1 transporter system (Munns and Tester, 2008), which allows to restore turgidity and thus to reinstall growth.

Alkalinity stress represents an accentuated version of salinity stress and is of vast agronomic impact with worldwide almost 1000 million hectares being affected (Rao et al., 2008). Although it is known that alkaline sodium stress has much harsher effects as compared to equimolar salinity at neutral pH (Wang et al., 2011), the molecular signals as well as the adaptive mechanisms are far from understood. In addition to osmotic challenge and ionic stress, alkalinity causes the precipitation of important nutrients including phosphates and metallic micronutrients, and also destroys the cellular structure of the roots (Li et al., 2009). Under physiological conditions, the apoplast is actively maintained at a slightly acidic $\mathrm{pH}$ of around 5.5 by proton ATPases localised in the plasma membrane and this activity is essential to sustain cell expansion growth (Haruta et al., 2010). Under alkaline conditions, this mechanism is interrupted. Moreover, the activity of osmotically induced calcium influx is expected to be impaired, because calcium enters the cell by cotransport with protons (which allows to conveniently monitoring this influx as transient alkalinization of the apoplast). As a second effect, the superoxide anions that are generated by the NADPH oxidase $\mathrm{RboH}$ to a certain extent even under normal conditions will not be dissipated due to the absence of protons as electron acceptors, leading to an accentuated stress-induced oxidative burst. Adaptation to alkalinity must involve mechanisms that transcend conventional salinity responses, a point that so far has not been appropriately considered in breeding programs (Bui, 2013). For instance, in addition to sequestering sodium in the vacuole, and quelling the accentuated oxidative burst, adaptation to alkalinity would also require powerful buffering of the apoplast, which might either be achieved through upregulation of proton ATPases or through secretion of organic acids.

The comparison of the three aspects of osmotic stress illustrates that each specific condition requires a specific adaptive response, which seems to be determined by specific equilibria 
between different stress inputs. This adaptive response is costly, however. For instance, stomatal closure will reduce water loss by transpiration, but it will also reduce photosynthetic efficiency and lead to secondary photooxidative stress caused by unbuffered electron transport in the thylakoid (Pinheiro and Chaves, 2011). Similarly, the synthesis of polyamines binds precious bioavailable nitrogen (Alcázar et al., 2006). Therefore, these adaptive responses have to be carefully adjusted to growth and development. It is this adjustment, where phytohormonal signaling links with stress adaptation. The jasmonate signaling system seems to act as a hub, where different inputs are processed to yield an appropriate adaptive response.

The following sections investigate the role of jasmonates for drought and salinity signaling and attempt to dissect the interaction of jasmonate signaling with the signaling triggered by ABA. Jasmonate biosynthesis utilizes different metabolites with potentially different biological activity. A complex feedback regulation of this pathway allows for each node to function in either direction to process several inputs with ample ramifications into different outputs as required for a signaling hub (Figure 1). Such a system acts in a highly non-linear fashion, which means that even subtle modulations in the relative activities of individual components of this hub can result in a qualitatively different output. This also means that breeding of stress-tolerant crops might not require drastic genetic changes. Slight, but targeted shifts in the relative activities of jasmonate signaling components might be worth exploring. This is particularly interesting in view of the independent evolution of salinity tolerance in some of the 3000 grasses (Bennett et al., 2013), which may be suggestive of perturbances in a limited number of pathways, but at different nodes. Thus, there may be more than one road leading to Rome.

\section{PLACING JASMONATES INTO THE DROUGHT AND SALINITY SIGNALING CASCADE}

Both drought and salt stress are multidimensional in nature and affect plants at various levels of their organization (Yordanov et al., 2000). Therefore, the effects of stress are often observed at morpho-physiological, biochemical and molecular levels, such as growth inhibition (Bahrani et al., 2010), enhanced production of compatible organic solutes (Sánchez-Díaz et al., 2008; DaCosta and Huang, 2009), changes in the content of phytohormones (Perales et al., 2005; Seki et al., 2007; Huang et al., 2008; Dobra et al., 2010; Kohli et al., 2013), or altered expression of stress responsive-genes (Xiong and Yang, 2003; YamaguchiShinozaki and Shinozaki, 2005; Huang et al., 2008). Changes tissue water status trigger some of these responses directly, while many others are brought about by plant hormone-dependent signaling (Chaves et al., 2003). The tolerance/adaptation response of plants to unfavorable environmental conditions strongly depends on chemical signals/secondary metabolites that are orchestrated by plant hormones in a complex balance between tolerance and growth (Sreenivasulu et al., 2012, Figure 1). It has been known previously that hormones do not function in discrete pathways, but rather influence each other at different levels (i.e., biosynthesis or signaling) to control environmental

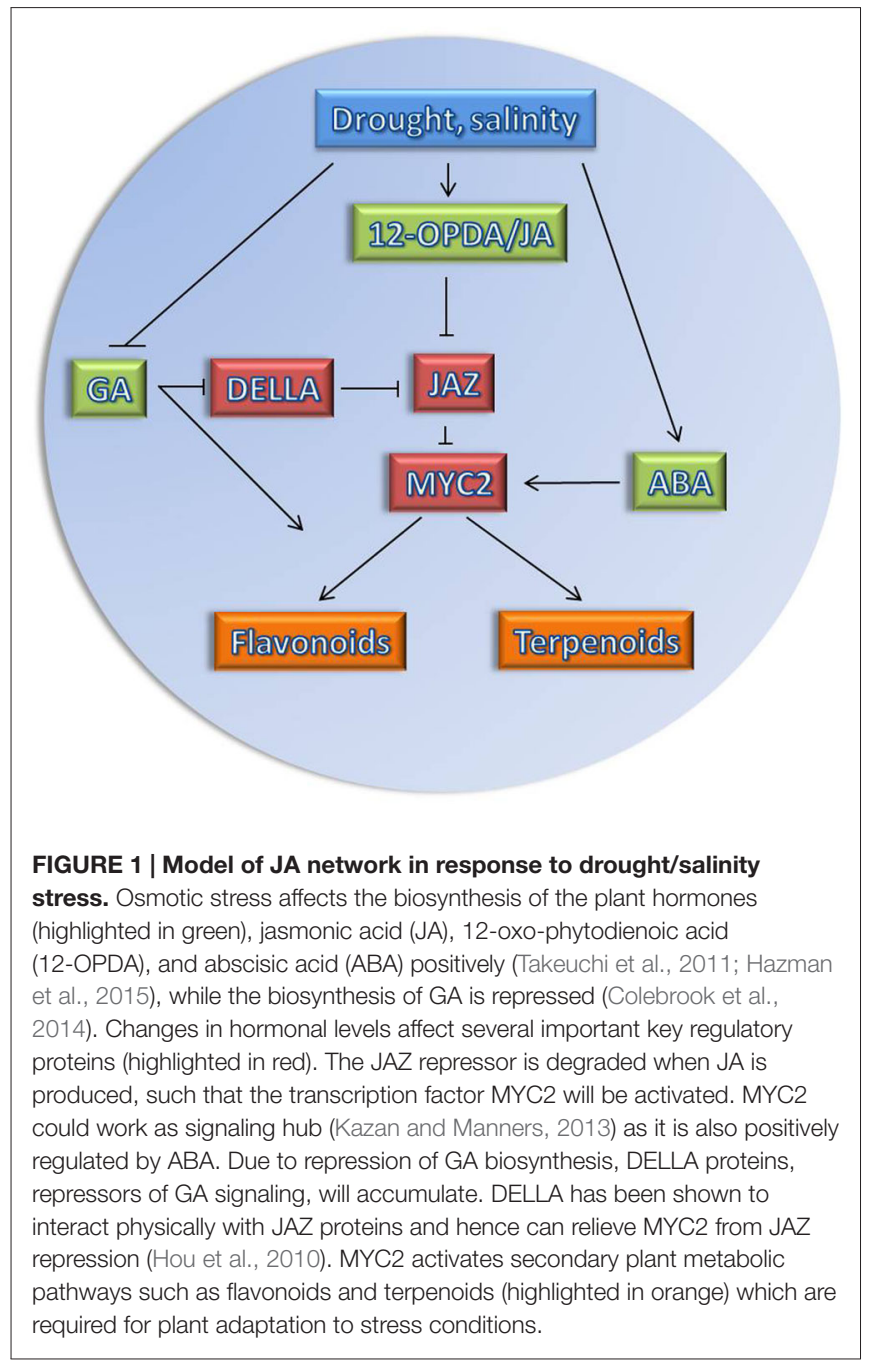

and developmental signaling pathways (Gray, 2004). This will create a signal transduction network that can integrate different inputs into a comprehensive output culminating in physiological adaptation of the plant to stress.

A key role in this hormonal network is played by the plant hormone ABA. Its function in the control of stomata closure and the responses to abiotic stress is well-established and has been intensively studied since decades (for review, see Mittler and Blumwald, 2015). Drought stress or high salinity cause accumulation of $\mathrm{ABA}$ in plants and extensive changes in gene expression (Shinozaki and Yamaguchi-Shinozaki, 2007). ABA signaling triggered by receptors in the plasma-membrane as well as the cytoplasm, has been intensively studied in guard cells (for review, see Mittler and Blumwald, 2015). Subsequent signaling increases the concentration of cytosolic $\mathrm{Ca}^{2+}$ due to the activation of calcium channels in the endoplasmic reticulum, which further activates or inhibits ion channels in the plasma membrane. As a result of ion fluxes, water potential in the apoplast decreases and water flows out of the cell leading to a lower turgor of guard cells and closure of stomata. Due to this central function of ABA for the regulation of stomatal opening and closure and the control over other stress adaptive mechanisms, this hormone is very important 
for the response to abiotic stress. However, usually changes in one hormonal pathway affects the pathways of other hormones and expectedly other hormones, especially those related to stress and growth responses, contribute to the overall response of the plant. One of these hormonal pathways currently attracting a lot of attention, is jasmonate signaling (JAs), conveyed by JA and its derivatives. JAs constitute a group of fatty acid-derived compounds that play prominent roles in coordinating inducible defense responses leading to increased tolerance to insect pests and necrotrophic pathogens (for review, see Wasternack and Hause, 2013). JAs are also required for specific steps of plant development like reproduction or photomorphogenesis (for review, see Svyatyna and Riemann, 2012). Biosynthesis, perception and action of JAs have been extensively studied. On the contrary, inactivation/removal mechanisms have remained elusive for a long time, but have been elucidated recently (Heitz et al., 2012; Aubert et al., 2015). In sharp contrast to most other plant hormones, JA must be activated by enzymatic coupling to isoleucine amino acid. The resulting JA-Ile functions as a ligand promoting assembly of a co-receptor complex between the F-box protein COI1 and so-called JA ZIM-domain (JAZ) proteins (Chini et al., 2007; Thines et al., 2007). JAZ proteins are transcriptional repressors that prevent the transcription of target genes under low JA-Ile levels, and are specifically ubiquitinated when JAIle accumulates under biotic stress. This is a signal leading to their proteolytic degradation, relieving active transcription of JA-responsive defense genes from repression (Figure 2). JAIle is therefore a master switch controlling various aspects of plant immunity/adaptation. Elements under JA control include the synthesis of digestive inhibitors targeting insects, volatile repellents, and many toxic or antimicrobial compounds that lower the performance of pests. Although role for jasmonates for the adaptation to salt stress has been suggested (Fujita et al., 2006), molecular mechanisms of the role of jasmonates for salt or drought stress-signaling are still mostly unclear. The following sections review what is known on how jasmonates contribute to the plant response toward these two intensively studied abiotic stresses, drought and high salinity.

\section{JASMONATES AND DROUGHT STRESS}

There is a steadily increasing body of evidence for the involvement of jasmonates in drought stress. Barley leaves exposed to simulated drought with sorbitol or mannitol exhibited increased endogenous contents of jasmonates, followed by the transcription of jasmonate-induced proteins (JIPs, Lehmann et al., 1995). A later study also showed that the contents of octadecanoids and JAs were enhanced by sorbitol treatment to a degree, sufficient to initiate JA-responsive gene expression (Kramell et al., 2000). In addition, endogenous JA content increased in maize root cells under drought stress (Xin et al., 1997), and this compound was also able to elicit betaine accumulation in pear leaves (Gao et al., 2004). In some studies, JA has been reported to improve drought tolerance but in others, it has been reported as a negative agent that causes notable reduction in growth and yield, hence the actual role of JA in drought stress remains controversial. Mostly, the observed responses depend on the type of plant and tissue in question, intensity and duration of drought stress and the dosage of JA applied (Lee et al., 1996; Kim et al., 2009). Therefore, a lot of the controversy might actually result from the fact that studies were done under different conditions, e.g., in various developmental stages, tissues, and with different stress regimes. This might be linked with the fact that also the degree of drought tolerance strongly depends on developmental stage in most plant species (Reddy et al., 2004; Rassaa et al., 2008).

\section{Exogenous Jasmonates can Increase Drought Tolerance}

Several reports suggest that exogenous application of jasmonates ameliorates the response of plants to drought stress. It has been reported that exogenous application of JA or MeJA increased the antioxidative capacity of plants under water stress (Bandurska et al., 2003). In the same context, other studies also showed that JAs play an important role in signaling drought-induced antioxidant responses, including ascorbate metabolism ( $\mathrm{Li}$ et al., 1998; Ai et al., 2008). It has been observed that exogenous JA is effective in protecting plants from drought-induced oxidative damage as it enhances the activity of antioxidant enzymes (Nafie et al., 2011). It is also hypothesized that MeJA could ameliorate water stress tolerance in banana by regulating the growth, proliferation rate, proline accumulation, chlorophyll levels, tissue water status, oxidative stress, and membrane lipid peroxidation (Mahmood et al., 2012).

Another study was conducted by Anjum et al. (2011) in soybean (Glycine max L. Merrill) to explore the role of exogenous MeJA application in alleviating the adversities of drought stress. Soybean plants were grown under normal conditions until blooming and then were subjected to drought by withholding water followed by foliar application of MeJA. From the observed data, it was noticed that drought stress substantially lowered the yield and yield-related traits, whereas it accelerated the peroxidation of membrane lipids. Nonetheless, considerable increase in the activity of antioxidant enzymes such as superoxide dismutase (SOD), peroxidase (POD), and catalase (CAT), and in proline, relative water contents (RWC) along with simultaneous decrease in membrane lipid peroxidation was observed when the drought stressed plants were treated by MeJA. These beneficial effects led to significant improvement in yield and harvest index under drought. Interestingly, MeJA application was also promotive under well-watered conditions. These results suggested that by modulating the peroxidation of membrane lipids and antioxidant activities, MeJA improved the drought tolerance of soybean.

\section{Which Jasmonates Contribute to Drought Stress Signaling?}

Jasmonates comprise a diverse group of JA derivatives (for review, see Wasternack and Hause, 2013), including its biosynthetic intermediate, 12-OPDA, which is capable of activating specific signaling events (Taki et al., 2005). Recent data indicate that 12-OPDA might be the jasmonate derivative which is mainly functional in the drought response.

De Domenico et al. (2012) measured the expression of key genes involved in oxylipin metabolism by quantitative PCR on 
samples from stressed and non-stressed roots of a droughttolerant and a drought-sensitive chickpea variety. In their study, they demonstrated that the drought tolerant variety reacts to drought with sustained and earlier activation of a specific lipoxygenase (MtLOX1), two hydroperoxide lyases (MtHPL1 and MtHPL2), an allene oxide synthase (MtAOS), and an oxophytodienoate reductase $(M t O P R)$. Over-expression of these genes correlated positively with the levels of major oxylipin metabolites from the allene oxide synthase (AOS) branch of the pathway, which finally leads to the synthesis of jasmonates. The roots of the tolerant variety accumulated higher levels of JA, its precursor OPDA and the active JA-Ile, suggesting a role of jasmonates for drought tolerance in chickpea.

Savchenko et al. (2014) identified that drought led to a block in the conversion of 12-OPDA to JA and further revealed that 12-OPDA was the functional convergence point of oxylipin and ABA biosynthesis pathways, to control stomatal aperture in plantadaptive responses to drought stress. They used three $A$. thaliana ecotypes to demonstrate that wounding induced both 12-OPDA and JA levels, whereas drought induced only the precursor 12OPDA. This implicated the AOS branch of the oxylipin pathway as a critical node. Levels of ABA were also mainly enhanced by drought and little by wounding. To explore more about the role of $12-O P D A$ in plant drought responses, they also generated a range of transgenic lines and exploited existing mutant plants that differ in their levels of stress-inducible 12-OPDA, but displayed similar ABA levels. The plants which were producing higher 12-OPDA levels exhibited enhanced drought tolerance and reduced stomatal aperture. Furthermore, on exogenous application of ABA and 12OPDA, whether individually or combined, stomatal closure was promoted in the ABA and AOS biosynthetic mutants, albeit most effectively when combined. Using tomato (Solanum lycopersicum) and Brassica napus, they verified the potency of this combination in inducing stomatal closure in plants other than Arabidopsis. They concluded that drought was a stress signal that uncoupled the conversion of 12-OPDA to JA and also revealed 12-OPDA as a drought-responsive regulator of stomatal closure functioning most effectively together with $\mathrm{ABA}$.

\section{Jasmonates Contribute to Regulation of Stomatal Closure}

Based on its accumulation during drought stress and its positive regulatory role in stomatal closure, JA has been proposed as important player for stomatal closure during drought stress (Gehring et al., 1997; Suhita et al., 2003, 2004). Soybean leaves under water stress showed a 15\% loss of fresh weight and accumulated fivefold more JA within $2 \mathrm{~h}$, but the level of JA declined to that of control plants by $4 \mathrm{~h}$ (Creelman and Mullet, 1995). MeJA-mediated stomatal closure has been related to cytoplasmic alkalinization in guard cells, production of ROS (via AtRboHD/F) and NO, and activation of K-efflux (Evans, 2003), as well as slow anion channels (Gehring et al., 1997; Suhita et al., 2003, 2004; Munemasa et al., 2007). All these effects are similar to those of ABA, thereby suggesting an overlapping use of signaling components for stomatal closure. This idea is also supported by observations made in the ABA hyposensitive ost1 mutant, which turned out to be less sensitive to MeJA with respect to stomatal closure. Moreover, the MeJA insensitive mutant jar1 displays reduced stomatal closure in response to ABA (Suhita et al., 2004).

\section{Do ABA and JA Act Synergistically in Drought Stress Signaling?}

Abscisic acid plays a key role in plant adaptation to adverse environmental conditions including drought stress. However, molecular, genetic and genomic analyses suggested that in addition to ABA-dependent pathways, ABA-independent regulatory systems are involved in stress-responsive gene expression (Bray, 1997; Shinozaki and Yamaguchi-Shinozaki, 1997, 2000; Riera et al., 2005). Induction of ABA synthesis is one of the fastest phytohormonal responses of plants to abiotic stress, thereby triggering ABA-inducible gene expression (YamaguchiShinozaki and Shinozaki, 2006), causing stomatal closure, and hence reducing water loss via transpiration (Wilkinson and Davies, 2010), which will eventually restrict cellular growth. During the adaptive responses of plants to environmental stresses, the overlap between hormone-regulated gene expression profiles suggests the existence of a complex network with extensive interactions between the different hormone signaling pathways. In order to examine a crosstalk between ABA and JA signal transduction Arabidopsis ABA-insensitive (ost1-2) and MeJA-insensitive (jar1-1) mutants were studied for the participation of ABA and JAs in stomatal closing (Suhita et al., 2004). The authors investigated changes of cytoplasmic $\mathrm{pH}$ and ROS production in response to $\mathrm{ABA}$ or JA, and the mutants were used to assess the respective roles of the mutated genes in ABA or JA signaling pathways leading to stomatal closure. The modulation of $\mathrm{Ca}^{2+}$ ions was induced by both, $\mathrm{ABA}$ and JA. However, the primary actions of ABA and JA in the plasma membrane appear to be different: JA targets the $\mathrm{Ca}^{2+}$ channels whereas ABA activates effectors in the plasma membrane (e.g., phospholipase C and D). However, at the level of intracellular $\mathrm{Ca}^{2+}$, both signal transduction pathways converge. Intracellular $\mathrm{Ca}^{2+}$ level is modulated to a much greater extent by JA than by ABA.

It is well established that JA biosynthesis is induced by stress conditions such as wounding and herbivory (Wasternack, 2007), but many JA-associated signaling genes are also regulated by drought stress (Huang et al., 2008). It has been shown that JA interacts with ABA-regulated stomatal closure by increasing $\mathrm{Ca}^{2+}$ influx, which activates a CDPK-dependent signal cascade. Treatment of turgescent, but excised Arabidopsis leaves with either ABA or MejA resulted in a reduction of stomatal aperture reduction within 10 min (Munemasa et al., 2007). Through the inhibition of $\mathrm{ABA}$ biosynthesis by chemical inhibitors or in ABA-deficient mutants, the MeJA-induced $\mathrm{Ca}^{2+}$ oscillations in guard cells are suppressed, and also stomatal closure is impaired (Hossain et al., 2011). Therefore, it has been postulated that MeJA-mediated regulation of stomatal closure interacts with ABA-mediated regulation of $\mathrm{Ca}^{2+}$ signal transduction pathways. Studies related to the interactions of ABA with MeJA in guard cells show that both hormones induce the formation of ROS and $\mathrm{NO}$, and also that both are present at reduced concentrations in MeJA-insensitive plants (Munemasa et al., 2007). 
The combined effect of ABA and JA for acclimation to stress in Arabidopsis may be mediated by an extensive genetic reprogramming to finally reach a new homeostasis (Harb et al., 2010). These authors suggested that endogenous JA together with high ABA level are sufficient to stimulate the preparatory response needed for drought acclimation (e.g., stomatal closure and cell wall modification) during the early stages of moderate drought (30\% field capacity). Probably, JA is not required at high concentration under drought stress, and plant growth would be even negatively impacted by high concentrations. For example, the JA-insensitive coil and jin 1, mutants of Arabidopsis were found to be significantly resistant (or insensitive) to moderate drought stress. Biomass accumulation as compared to wild type under drought did not differ from the well-watered control. These results were in agreement with studies showing that the JA-mediated inhibition of seedling and root growth is suppressed in the coil mutant (Xie et al., 1998). Harb et al. (2010) suggested that in the absence of JA signal perception, the developmental program for acclimation to stress, i.e., reduced growth is not switched on. Thus, the signaling pathways for plant growth under prolonged drought might converge on the down-regulation of JA biosynthesis to minimize its inhibitory effect on plant growth, thus establishing a new state of homeostasis by the acclimation process.

The proposed overlap between the JA and ABA stress signaling cascades (Fujita et al., 2006; Harb et al., 2010) has stimulated the search for transcription factors and kinases as promising candidates for common players in this interaction. For example, the transcription factor AtMYC2 plays a role in multiple hormone signaling pathways. From the genetic analysis of the jasmonateinsensitive jin1 mutant, it was revealed that JIN1 is allelic to AtMYC2, which was first identified as a transcriptional activator that is involved in the ABA mediated drought-stress signaling pathway (Abe et al., 2003). Downstream targets, such as RD22, a gene responsive to dessication and salt stress, is activated by both, AtMYC2 and R2R3MYB-type, transcription factors. Similarly, expression of $R D 26$ is induced by hydrogen peroxide, pathogen infections, and JA, as well as by drought, high salinity and ABA treatment (Fujita et al., 2004, 2006; Harb et al., 2010). In addition, protein phosphorylation and dephosphorylation by kinases and phosphatases, respectively, can significantly affect the regulation of morpho-physiology and gene expression associated with JAdependent root growth. However, enzymes phosphorylating or dephosphorylating AtMYC2 have not been identified yet (Kazan and Manners, 2008).

To specifically address the crosstalk of ABA and JA at the whole plant level, the tomato ABA-biosynthetic mutant sitiens was used. When the petioles of sitiens were incubated in JA, they did not show any indications of stomatal closure as assessed by gas-exchange measurements; however, when pre-incubated with ABA, petioles showed stomatal closure in response to JA (Herde et al., 1997). This suggested that in tomato, ABA was required for the JA-mediated stomatal regulation. In soybean, it was observed that exogenous application of MeJA did not affect endogenous ABA levels. However, water stressed barley seedlings that had been pre-treated with JA showed more than fourfold accumulation of ABA in comparison to the control. This clearly suggested a role for JA in ABA biosynthesis under water stress conditions (Bandurska et al., 2003). MeJA regulates numerous drought-responsive genes (Huang et al., 2008), many of which are also regulated by $\mathrm{ABA}$ with similar expression kinetics (Nemhauser et al., 2006; Huang et al., 2008). Overall, all these data support the concept of common signaling components for $\mathrm{ABA}$ and MeJA, including nitric oxide (NO; for review, see Daszkowska-Golec and Szarejko, 2013).

\section{Involvement of Jasmonates in the Drought Response in Rice}

Substantial information exists about the roles of phytohormones under drought in model plants such as Arabidopsis. A current challenge is to transfer this knowledge to other, economically more relevant, plant species. Two examples of investigations performed in rice are presented as case studies.

Seo et al. (2011) used a functional genomics approach that identified a basic helix-loop-helix domain gene (OsbHLH148) that conferred drought tolerance as a component of the jasmonate signaling module in rice. They found that OsbHLH148 transcript levels were rapidly increased by treatment with MeJA or ABA, as well as by abiotic stresses including dehydration, high salinity, low temperature and wounding. Over-expression of OsbHLH148 in rice conferred tolerance to drought stress. Expression profiling followed by DNA microarray and RNA gel-blot analyses of transgenic versus wild type rice identified genes that were up-regulated by over-expression of OsbHLH148. These genes included $O S D R E B$ and $O S J A Z$, genes involved in osmotic stress responses and jasmonate signaling, respectively. OsJAZ1, a rice ZIM domain protein, interacted with OsbHLH148 in yeast two-hybrid and pull-down assays and it interacted with the putative OsCOI1 only in the presence of coronatine. Furthermore, the OsJAZ1 protein was degraded by rice and Arabidopsis extracts in the presence of coronatine, and its degradation was inhibited by MG132 which is a $26 \mathrm{~S}$ proteasome inhibitor, suggesting $26 \mathrm{~S}$ proteasome-mediated degradation of OsJAZ1 via the SCF ${ }^{\text {OsCOI1 }}$ complex. These results suggested that OsJAZ1 was a transcriptional regulator of the OsbHLH148-related jasmonate signaling pathway leading to drought tolerance, suggesting that OsbHLH148, OsJAZ, and OsCOI1 constitute a signaling module in rice.

Another study by Kim et al. (2009) demonstrated that constitutive overexpression of the Arabidopsis JASMONIC ACID CARBOXYL METHYLTRANSFERASE gene (AtJMT) in rice increased the levels of MeJA by sixfold in young panicles in rice. Grain yield was greatly reduced due to lower number of spikelets and lower grain-filling rate as compared to non-transgenic (NT) controls. The number of spikelet organs, including the lemma/palea, lodicule, anther, and pistil were altered in these transgenic plants. The loss of grain yield and alteration in spikelet organ numbers were reproduced by treating NT plants with exogenous application of MeJA, thereby indicating that it was the increased levels of MeJA in the AtJMT transgenic rice panicles, that was responsible for the inhibition of spikelet development. Interestingly, in young NT panicles upon exposure to drought conditions, MeJA levels were increased by 19-fold resulting in a similar loss of grain yield. ABA levels were increased by 1.9and 1.4-fold in the transgenic and drought-treated NT panicles 
respectively. Increased levels of ABA in the AtJMT transgenic panicles grown in non-drought conditions suggests that it is MeJA, and not drought stress, which induces ABA biosynthesis under drought. A microarray strategy identified seven genes commonly regulated in the AtJMT transgenic and drought-treated NT panicles. Two of these genes, namely OsJMT1 and OsSDR (for short-chain alcohol dehydrogenase), participate in rice in the biosynthesis of MeJA and ABA, respectively. Overall, these results suggested that plants produce MeJA during drought stress, which in turn stimulates the production of $\mathrm{ABA}$, leading to a loss of grain yield.

The two examples above establish the importance of further studies exploring the role of JAs in combating drought stress in rice. Similar studies in other cereals may also be helpful in delineating the role of JA individually or in combination with other phytohormones toward understanding the plant response to drought and toward generating more resilient cereal plant varieties.

\section{JASMONATES AND SALT STRESS: A RELATION NOT EASY TO BE FIGURED OUT}

Salinity stress is at least as complex as drought stress. Initially, it mainly triggers three harmful effects, (i) osmotic stress (reduced water uptake),(ii) specific ion toxicity stress (mainly $\mathrm{Na}^{+} \mathrm{ad} \mathrm{Cl}^{-}$), and (iii) oxidative stress by uncontrolled production of ROS, including superoxide radicals $\left(\mathrm{O}_{2}\right)$, hydrogen peroxide $\left(\mathrm{H}_{2} \mathrm{O}_{2}\right)$, and hydroxyl radicals $\left(\mathrm{OH}^{-}\right)$. These ROS can cause oxidative damage to proteins, enzymes, DNA and RNA (Pessarakli, 2001; Sharma et al., 2012), but can also act as important stress signals. After their role in osmotic stress has been discussed above, now the role of jasmonates in the context of ion toxicity and oxidative stress will be addressed.

Several reports investigated the involvement of JA in salt stress. On the one hand, application of exogenous JAs diminished the damage by salinity in soybean (Yoon et al., 2009) and rice (Kang et al., 2005). On the other hand, the level of endogenous JAs increased under strong salt stress in rice roots (Moons et al., 1997) and in tomato (Pedranzani et al., 2007) suggesting that accumulation of JAs could also protect against salt stress. Nevertheless, it is not possible to draw a general connection between high levels of JA and adaptation. For example, a comparison of two grapevine cell lines differing in their salinity tolerance revealed that the accumulation of JA and JA-Ile was more pronounced in the sensitive Vitis riparia than in the salttolerant Vitis rupestris (Ismail et al., 2012, 2014a). Also, JA was induced after osmotic stress but not after salt stress in barley segments (Kramell et al., 2000) and rice seedlings (Takeuchi et al., 2011). Recent evidence suggests that alterations in the level of JAs affect salinity tolerance in rice. Kurotani et al. (2015) demonstrated that overexpression of CYP94, a gene encoding a catabolic enzyme inactivating JA-Ile, results in improved salt tolerance. Suppression of OsJAZ9, a repressor of JA signaling, produced higher sensitivity to JA and an increased sensitivity to salt (Wu et al., 2015). Conversely, rice mutants of the JA biosynthesis enzyme AOC, hebiba, and cpm2, showed an improved salt tolerance (Hazman et al., 2015). Whether it is the lack of JA or JA-Ile, or whether it is the absence of their precursor 12-OPDA which causes this tolerance, remains to be elucidated. The discrepancies with respect to the role of JAs for salt tolerance indicate that it may not be the presence or absence of JAs that decides the kind of response to salinity, but their timing and control, which may be more important (Ismail et al., 2014b).

\section{Evidence for the Involvement of Jasmonates in the Uptake of Sodium Ions}

In order to cope successfully with high salinity stress, it is necessary for plants to reduce the accumulation of sodium ions into the photosynthetic tissue. This holds especially true for glycophytes to which many important economic crops belong. Currently, it is not clear, whether and how extra- or intracellular sodium ions are sensed, there is no evidence for a receptor of sodium ions in sensu stricto (Zhu, 2007). Even though the molecular identity of $\mathrm{Na}^{+}$sensors has remained elusive, the plasma membrane $\mathrm{Na}^{+} / \mathrm{H}^{+}$antiporter SOS1 might be a probable candidate (Shi et al., 2000). The transport activity of SOS1 is essential for sodium efflux from Arabidopsis cells but additionally, its long cytoplasmic tail can bind $\mathrm{Na}^{+}$and might therefore confer sodium sensing (Conde et al., 2011). The JA biosynthesis genes ALLENE OXIDE SYNTHASE (AOS) and ALLENE OXIDE CYCLASE (AOC) have been reported to be highly expressed in response to salinity in a SOS-dependent manner (Gong et al., 2001), suggesting a shared pathway. However, the exact link between jasmonates and SOS1 on the level of signaling and functional interactions is far from clear.

It is well known that the plasma membrane around the root hair epidermal cells is responsible for the influx of the largest portion of sodium ions into plant cells at the soil-plant interface. Several candidate genes have been reported as responsible for $\mathrm{Na}^{+}$ uptake in plants including NSCCs, high-affinity $\mathrm{K}^{+}$transporters (HKTs), and low-affinity cation transporter (LCT1; Schachtman et al., 1997; Apse and Blumwald, 2007; Craig Plett and Møller, 2010). Additionally and equally important, controlling potassium supply during salinity stress is the main key for survival as the $\mathrm{K}^{+} / \mathrm{Na}^{+}$ratio should be kept as high as possible for avoiding metabolic failure due to sodium toxicity (Kronzucker et al., 2013). Uptake of sodium ions into rice depends on jasmonates (Hazman et al., 2015), since the aoc mutants hebiba and cpm2 accumulated significantly less sodium ions in their shoots, indicating that selective transporters, presumably located in the Casparian strip in the root, might be regulated by jasmonates. It is likely that this trait vary between species and even between cultivars within the same species, which might be one of the reasons, why salt tolerant and salt sensitive cultivars can accumulate different levels of JAs in response to salt stress.

\section{JASMONATE CROSSTALK TO OTHER PHYTOHORMONES IN ABIOTIC STRESS SIGNALING}

In the previous sections, JA crosstalk to $\mathrm{ABA}$ and the involvement of protein phosphorylation (e.g., of MYC2) and ubiquitination 


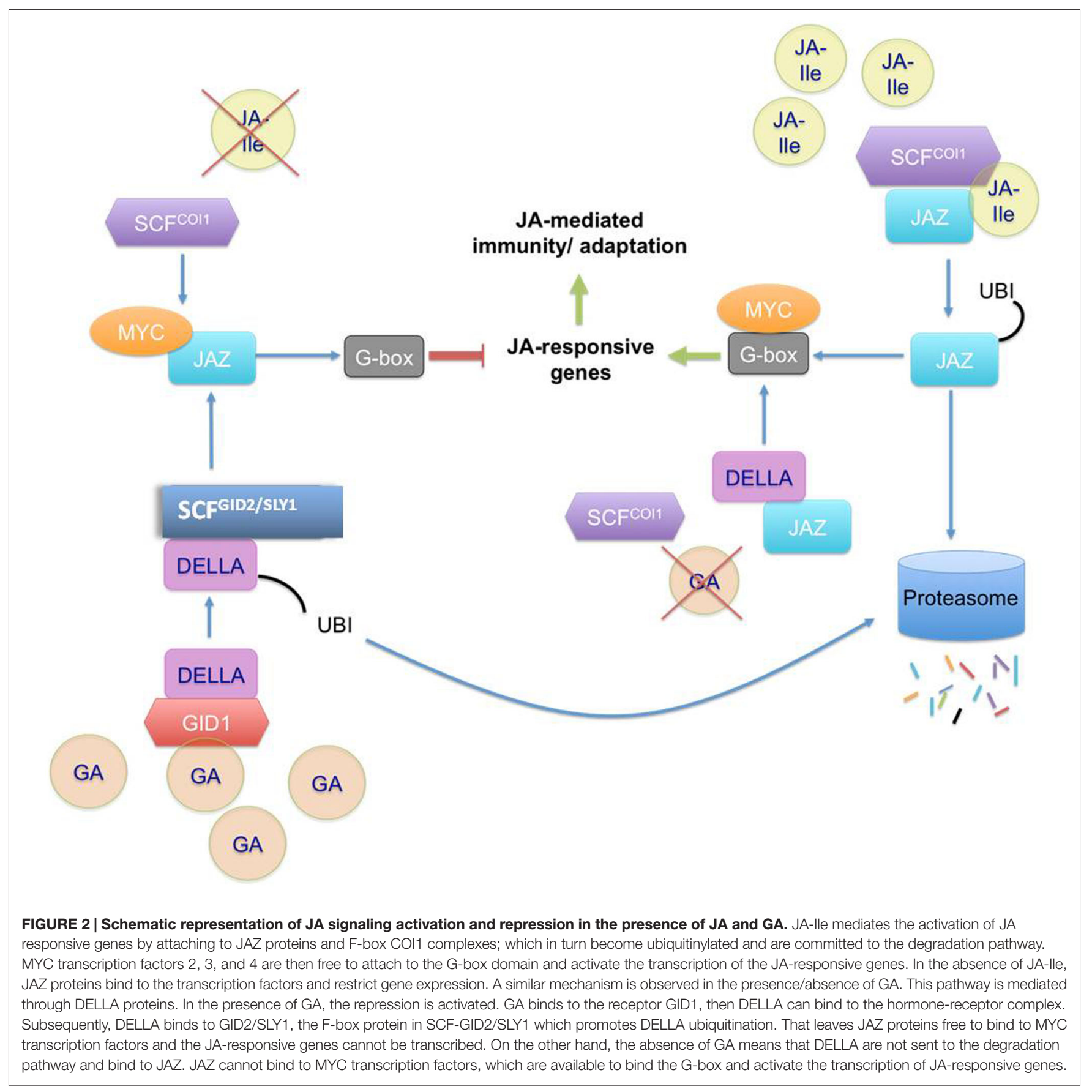

(e.g., of JAZ repressors) as downstream effects of JA have been mentioned. Although the JA and ABA crosstalk for the regulation of stomatal opening is important, especially under drought, this seems to be not the only crosstalk of JA with other phytohormones or signaling molecules.

Gibberellic acid (GA), generally known as growth hormone, plays also a role in abiotic stress tolerance. The content of GAs may be involved in either growth suppression or promotion under a specific abiotic stress (Colebrook et al., 2014). Crosstalk between GA and JA can be mediated through the DELLA and JAZ proteins which directly interact with each other. This interaction would compete with the JAZ proteins binding to MYC2, a transcription factor activating JA responsive genes, whereby JAZ proteins negatively regulate the JA response. In the presence of JA, the JAZ proteins are committed to proteasome-mediated degradation, while in the presence of GA the DELLA proteins are recruited for proteasome-mediated degradation (Figure 2). Thus, in presence of GA, the JAZ proteins can again bind to MYC2, the alternate partner, and attenuate JA-responsive genes (Boter et al., 2004; Hou et al., 2010). Interestingly, a DELLA gene $R G L 3$ is transcriptionally upregulated by JA signaling, and the promotor of RGL3 is a target of MYC2 (Wild et al., 2012). RGL3 
physically interacts with JAZ1 and JAZ8, the latter being relatively resistant to JA-mediated degradation (Shyu et al., 2012; Wild et al., 2012). Thus, JA-mediated degradation of JAZ1 releases MYC2 to induce $R G L 3$, which in turn binds the non-JA degradable JAZ8 enhancing the MYC2-dependent JA responses (Wild et al., 2012). Further, the GA content determines the extent of degradation of DELLA proteins, and thus the induction amplitude for the JA response, thus linking the two hormone signaling pathways. GA and ABA crosstalk follows a similar pattern under abiotic stress through another DELLA target (Ko et al., 2006; Zentella et al., 2007).

Interaction between auxins including the main natural auxin indole-3-acetic acid (IAA) and JA during plant growth and development have been described including phenomena such as cell elongation, abscission, and tendril coiling, but also wound responses (Saniewski et al., 2002). Recently Du et al. (2013) documented interactions between IAA and JA under drought in rice. Analysis of transcripts related to auxin and JA biosynthesis or signaling showed increased expression of auxin related genes under heat and cold, but a decrease under drought, which was paralleled by corresponding changes of IAA content. However, the content of JA and its associated genes increased under drought and cold but decreased under heat stress. Tiryaki and Staswick (2002) showed that the expression of JA-responsive genes was either repressed or induced by exogenous auxin, suggesting that JA- and auxin-triggered signaling can interact both antagonistically or synergistically. The underlying mechanisms as well as the biological context is far from understood, but one point of convergence might be the GH3 family of acyl acid amido synthetases which contribute to amino acid conjugation of both IAA and JA, which in case of JA generates the active signal, whereas it might be a mechanism of inactivation in case of IAA (Staswick et al., 2005; Khan and Stone, 2007). JA and auxin crosstalk during JA induced lateral root formation involving the ethylene response factor 109 (ERF109) was reported by Cai et al. (2014), and Jiang et al. (2014) recently reported that, in Arabidopsis, the WRKY57 acts as a node of convergence in JA and IAA-mediated signaling during JA-induced leaf senescence. Arabidopsis JAZ4/8 and IAA29, repressors of JA and IAA signaling, respectively, both competitively bind WRKY57, which is upregulated by IAA, but downregulated by JA. A rice AUX/IAA protein, OsIAA6 has been shown to correlate with drought tolerance in rice (Jung et al., 2015). Thus, JAZ, IAA, ARF, and WRKY genes are known to be act positively on drought tolerance, but the mechanisms of their interaction are yet to be elucidated.

Cytokinins (CK) as further important class of phytohormones driving cell division and meristem formation might also interact with JA signaling. The crosstalk between JA and auxin during meristem formation is well documented (Su et al., 2011), but, so far, there is not much evidence for interplay between JA and CK. However, the two hormonal pathways might be linked antagonistically (Sano et al., 1996; Naik et al., 2002; StoynovaBakalova et al., 2008). CK content in vivo and application of exogenous $\mathrm{CK}$ accelerate the JA-mediated stress response (Sano et al., 1996; Dervinis et al., 2010), while JA application induces the accumulation of CK ribosides (Dermastia et al., 1994). JA biosynthesis is activated in the roots during drought (Poltronieri et al., 2013), and repression of CK biosynthesis and signaling promotes the expansion of the root system, which should act positively on drought tolerance (Werner et al., 2010). Thus, JA and CK signaling/biosynthesis might mainly act in an antagonistic manner.

Similar to JA, also salicylic acid (SA) has been classically associated with biotic stress. However, a combined approach of proteomics and transcriptomics identified common proteins upregulated by JA and SA, associated with oxidative or abiotic stress responses (Proietti et al., 2013). On the other hand, SA can quell the induction of AOS in response to wounding, demonstrating a negative crosstalk from SA upon JA signaling (Harms et al., 1998). The role of SA under abiotic stresses including heat, salt and osmotic stress is well accepted and has been extensively reviewed (Horváth et al., 2007; Pal et al., 2013; Miura and Tada, 2014). The convergence between the JA and SA signaling in Arabidopsis was identified as the MAP Kinase 4 (AtMPK4), which negatively regulates the activation of SAand the repression of JA-mediated defenses under biotic stress (Brodersen et al., 2006). Whether AtMPK4 exerts the same function under abiotic stress remains to be tested, but it is already known that AtMAPK4 is rapidly activated by abiotic stresses (Ichimura et al., 2000). In this regard the role of SA in stomatal closure is noteworthy (Miura and Tada, 2014).

Crosstalk between JA and ethylene is well known for defense against plant pests and pathogens. Once again, however, importance of such crosstalk between JA and ET in abiotic stress has been elaborated only recently (Kazan, 2015). The expression of the Arabidopsis ethylene response factor 1 (AtERF1) is activated by both JA and ET (Lorenzo et al., 2003). It has now been reported that synergistic activation of AtERF1 is required for drought and salinity tolerance (Cheng et al., 2013). Constitutive overexpression of AtERF1 additionally produced enhanced tolerance to heat as well. The set of genes upregulated in the AtERF1 overexpression plants can be assigned to heat, drought, salt and JA responses, respectively, but unlike for biotic stress, these genes are activated through binding of ERF1 to the dehydration response element (DRE) rather than to the GCC element (Cheng et al., 2013). For the salt stress response in tobacco, JA connects not only with ET, through a jasmonate responsive tomato ERF (JERF1), but also with ABA signaling (Zhang et al., 2004). Also a second tomato ERF (SlERF.B.3) is linked with the response to salt and cold stress (Klay et al., 2014).

The JA crosstalk to brassinosteroids has also been documented. Brassinosteroids were shown to negatively regulate the JA inhibition of root growth, the point of convergence being the F-Box protein coronatine insensitive 1 (COI1) required for JA response (Ren et al., 2009). Inhibition of JA induced accumulation of anthocyanins by brassinazole in Arabidopsis represents a second example for a negative impact of brassinosteroid signaling upon the JA pathway (Peng et al., 2011). In this interaction between JA and brassinosteroids the WD-repeat/Myb/bHLH transcriptional complexes were implicated (Qi et al., 2011). Concordance was shown between anthocyanins and drought tolerance in rice and Arabidopsis (Basu et al., 2010; Sperdouli and Moustakas, 2012), thus implicating a role for JA. Divi et al. (2010) reported on the 
crosstalk between brassinosteroids, ET, SA, JA, and ABA using mutants in the respective phytohormone biosynthesis pathways. Recently the same authors studied the brassinosteroids-mediated stress tolerance and found distinct molecular signatures of ABA and JA (Divi et al., 2015).

Nitric oxide has emerged as a major signal affecting the JA, SA, and ET signaling in biotic stress response, and has meanwhile also been shown to act in abiotic stress responses as well (Wang et al., 2006; Song et al., 2008; Huang et al., 2009; Zhang et al., 2011). In this context, the role of NO in stomatal aperture has attracted most attention, because guard cells have emerged as convenient model system to dissect signaling cascades. The first tier of signaling is formed by $\mathrm{pH}$, ROS, free $\mathrm{Ca}^{2+}$, and phospholipid activating the next layer of signaling by complex interactions of these primary signals with ABA, ET, JA, and NO (Gayatri et al., 2013). By treatment with NG-nitro-L-arginine methyl ester (L-NAME), an inhibitor of NO synthase (Xin et al., 2005), jasmonate-induced stomatal closure could be modulated indicating that $\mathrm{NO}$ acts downstream of JA. Like in most cases of signal crosstalk, specific roles, timing and convergence points of NO and JA signaling are still not characterized, which would be a precondition for strategies to promote plant tolerance to abiotic stress.

\section{PROTEIN POST-TRANSLATIONAL MODIFICATION AND JASMONATES CROSSTALK}

Post-translational modifications (PTM) regulate many proteins critical for JA biosynthesis and their signaling crosstalk with other phytohormones. Among the various possible protein modifications, protein phosphorylation, ubiquitination and SUMOylation have been in focus for these pathways. For example, PPS3 the potato homolog of Arabidopsis JAI3/JAZ3, is phosphorylated by StMPK1, the MPK6 homolog of Arabidopsis MAP kinase (Katou et al., 2005). Dephosphorylation of proteins involved in regulating JA content has also been shown (Schweighofer et al., 2007).

In JA signaling, an important role is played by the JAZ and the DELLA proteins, both of which are ubiquitinated in the presence of jasmonates and gibberellins, respectively, and undergo proteasome-mediated degradation. JAZ degradation leads to transcriptional activation and DELLA degradation leads to repression of the JA responsive genes by MYC2 (Figure 2). Recently, SUMOylation of DELLA was shown to sustain DELLAmediated inhibition of growth under stress (Conti et al., 2014). SUMOylated DELLAs bind to the SUMO interacting motif of the GA receptor GID1 whose sequestration leads to an accumulation of non-SUMOylated DELLAs. It remains to be seen if in such conditions the SUMOylated or non-SUMOylated content of the DELLAs leads to their altered interaction with the JAZ proteins and influences the activity of the JA responsive genes.

The identification of auxin-resistant1 (axrl) mutants with altered jasmonate responsive gene expression during screening for mutants resistant to MeJA- and auxin-mediated growth inhibition indicated JA-auxin crosstalk (Tiryaki and Staswick, 2002). AXR1 encodes an enzyme that activates a second small protein related to ubiquitin (RUB1; Nedd8 in mammals). Therefore, both jasmonate and auxin signal transduction depends on small modifier proteins (Lorenzo and Solano, 2005).

Salicylic acid signaling is controlled by a SUMO E3 ligase (SIZ1) whereby siz1 mutants of Arabidopsis accumulate SA (Lee et al., 2007). SIZ1 is also known to regulate drought responses without the involvement of DREB2A and ABA, with the expression of nearly $10 \%$ of the drought inducible genes being mediated by SIZ1 (Catala et al., 2007). These genes also include some for JA responses. Down-regulation of 11 genes of the brassinosteroid biosynthesis and signaling pathway was noted through the genome-wide expression analysis of the sizl mutants. This suggested an important role for protein SUMOylation in these pathways (Catala et al., 2007).

Interestingly, NO content is highly influenced by the SUMOylation of the nitrate reductases (NRs) NIA1 and NIA2, and SUMOylation substantially increases the activity of the two NRs (Park et al., 2011). Finally, SIZ1, the SUMO E3 ligase, is also involved in copper homeostasis putatively through regulating the metal transporters YELLOW STRIPE LIKE (YSL1 and YSL3; Chen et al., 2011), which affects ethylene perception (Burkhead et al., 2009).

Apparently, SUMO conjugation-deconjugation to proteins plays an important role in abiotic stress (Castro et al., 2012; Raorane et al., 2013). This section implies that a number of effects of SUMO on abiotic stress may be mediated through affecting phytohormone biosynthesis and signaling crosstalk. When phytohormone crosstalk is so intricately linked that spatiotemporal signatures of active hormone content are the defining features, rather than overall content, PTM of the proteins involved in the various crosstalk routes becomes a regulatory feature that is likely as important as their transcription and translation per se. For a holistic understanding of JAs as emerging molecules of importance in abiotic stress tolerance, not only their crosstalk to other phytohormones but also the protein PTM aspects must be deeply explored.

\section{CAN FINE-TUNING OF THE JASMONATE PATHWAY LEAD TO ABIOTIC STRESS TOLERANCE?}

Plants can resist abiotic stresses through several distinct mechanisms, but the traits associated with resistance mechanisms are multigenic, often converging on genes shared by different stresses. Under stress conditions, the interactions happening between signaling pathways and their biological significance still remain unclear. As of now, these pathways are getting better resolved due to the evolution of new tools that allow the exploration of the physiological, genetic, and biochemical basis of such processes. The use of genomic, proteomic, and metabolomic approaches is gaining grounds not only in model plants such as Arabidopsis but also in crops such as rice. These investigative strategies will unravel new crosstalks between the different classes of stress hormones (for review, see, e.g., Kazan, 2015).

Keeping in view the immense losses caused by adverse environmental conditions like drought or salinity, there is an immediate need to develop new crop varieties with better adaptability or enhanced tolerance. Till date only a handful of labs 
around the world have been able to show a direct relation between JA functioning as a stress hormone in salinity and drought tolerance. The examples discussed here present a substantial reason to suggest a central role of JA as a hormone for these stress responses. More research focus in this direction will help to explain various drought stress responses and provide powerful tools for improving drought tolerance in plants and to develop new drought tolerant varieties. However, it will be a big challenge to manipulate JA biosynthesis or signaling without giving rise to negative side effects commonly associated with reduced jasmonate function such as reduced fertility and enhanced sensitivity to pathogens. Finding the critical nodes in the phytohormone biosynthetic pathways, whose manipulation can be useful for stress tolerance without the associated penalties; will largely define

\section{REFERENCES}

Abe, H., Urao, T., Ito, T., Seki, M., Shinozaki, K., and Yamaguchi-Shinozaki, K. (2003). Arabidopsis AtMYC2 (bHLH) and AtMYB2 (MYB) function as transcriptional activators in abscisic acid signaling. Plant Cell 15, 63-78. doi: 10.1105/tpc.006130

Ai, L., Li, Z. H., Xie, Z. X., Tian, X. L., Eneji, A. E., and Duan, L. S. (2008). Coronatine alleviates polyethylene glycol-induced water stress in two rice (Oryza sativa L.) cultivars. J. Agron. Crop. Sci. 194, 360-368. doi: 10.1111/j.1439037X.2008.00325.x

Alcázar, R., Marco, F., Cuevas, J. C., Patron, M., Ferrando, A., and Carrasco, P. (2006). Involvement of polyamines in plant response to abiotic stress. Biotechnol. Lett. 28, 1867-1876. doi: 10.1007/s10529-006-9179-3

Allen, G. J., Chu, S. P., Schumacher, K., Shimazaki, C. T., Vafeados, D., Kemper, A., et al. (2000). Alteration of stimulus-specific guard cell calcium oscillations and stomatal closing in Arabidopsis det3 mutant. Science 289, 2338-2342. doi: 10.1126/science.289.5488.2338

Anjum, S. A., Xie, X., Farooq, M., Wang, L., Xue, L., Shahbaz, M., et al. (2011). Effect of exogenous methyl jasmonate on growth, gas exchange and chlorophyll contents of soybean subjected to drought. Afr. J. Biotechnol. 10, 9640-9646.

Apse, M. P., and Blumwald, E. (2007). $\mathrm{Na}^{+}$transport in plants. FEBS Lett. 581, 2247-2254. doi: 10.1016/j.febslet.2007.04.014

Aubert, Y., Widemann, E., Miesch, L., Pinot, F., and Heitz, T. (2015). CYP94mediated jasmonoyl-isoleucine hormone oxidation shapes jasmonate profiles and attenuates defence responses to Botrytis cinerea infection. J. Exp. Bot. 3879-3892. doi: 10.1093/jxb/erv190

Bahrani, M. J., Bahrami, H., and Haghighi, A. A. K. (2010). Effect of water stress on ten forage grasses native or introduced to Iran. Grassl. Sci. 56, 1-5. doi: 10.1111/j.1744-697X.2009.00165.x

Bandurska, H., Stroiński, A., and Kubiś, J. (2003). The effect of jasmonic acid on the accumulation of ABA, proline and spermidine and its influence on membrane injury under water deficit in two barley genotypes. Acta Physiol. Plant. 25, 279-285. doi: 10.1007/s11738-003-0009-0

Basu, S., Roychoudhury, A., Saha, P. P., and Sengupta, D. N. (2010). Differential antioxidative responses of indica rice cultivars to drought stress. Plant Growth Regul. 60, 51-59. doi: 10.1007/s10725-009-9418-4

Bennett, T. H., Flowers, T. J., and Bromham, L. (2013). Repeated evolution of salt-tolerance in grasses. Biol. Lett. 9, 20130029. doi: 10.1098/rsbl.2013. 0029

Boter, M., Ruíz-Rivero, O., Abdeen, A., and Prat, S. (2004). Conserved MYC transcription factors play a key role in jasmonate signaling both in tomato and Arabidopsis. Genes Dev. 18, 1577-1591. doi: 10.1101/gad.297704

Bray, E. A. (1997). Plant responses to water deficit. Trends Plant Sci. 2, 48-54. doi: 10.1016/S1360-1385(97)82562-9

Brodersen, P., Petersen, M., Bjørn Nielsen, H., Zhu, S., Newman, M. A., Shokat, K. M., et al. (2006). Arabidopsis MAP kinase 4 regulates salicylic acid- and jasmonic acid/ethylene-dependent responses via EDS1 and PAD4. Plant J. 47, 532-546. doi: 10.1111/j.1365-313X.2006.02806.x

Bui, E. (2013). Possible role of soil alkalinity in plant breeding for salt-tolerance. Biol. Lett. 9:20130566. doi: 10.1098/rsbl.2013.0566 the level of success in utilizing these pathways for breeding stress tolerant crop varieties.

\section{AUTHOR CONTRIBUTIONS}

MR, RD, MH, BM, AK, and PN drafted the manuscript. BM and $\mathrm{MR}$ designed the figures. $\mathrm{MR}, \mathrm{RD}, \mathrm{AK}$, and $\mathrm{PN}$ revised the manuscript.

\section{ACKNOWLEDGMENTS}

We acknowledge support by Deutsche Forschungsgemeinschaft and Open Access Publishing Fund of Karlsruhe Institute of Technology.

Burkhead, J. L., Reynolds, K. A. G., Abdel-Ghany, S. E., Cohu, C. M., and Pilon, M. (2009). Copper homeostasis. New Phytol. 182, 799-816. doi: 10.1111/j.14698137.2009.02846.x

Cai, X. T., Xu, P., Zhao, P. X., Liu, R., Yu, L. H., and Xiang, C. B. (2014). Arabidopsis ERF109 mediates cross-talk between jasmonic acid and auxin biosynthesis during lateral root formation. Nat. Commun. 5, 5833. doi: 10.1038/ncomms6833

Castro, P. H., Tavares, R. M., Bejarano, E. R., and Azevedo, H. (2012). SUMO, a heavyweight player in plant abiotic stress responses. Cell. Mol. Life Sci. 69, 3269-3283. doi: 10.1007/s00018-012-1094-2

Catala, R., Ouyang, J., Abreu, I. A., Hu, Y., Seo, H., Zhang, X., et al. (2007). The Arabidopsis E3 SUMO ligase SIZ1 regulates plant growth and drought responses. Plant Cell 19, 2952-2966. doi: 10.1105/tpc.106.049981

Chaves, M. M., Maroco, J. P., and Pereira, J. S. (2003). Understanding plant responses to drought from genes to the whole plants. Funct. Plant Biol. 30, 239-264. doi: 10.1071/FP02076

Chen, C. C., Chen, Y. Y., Tang, I. C., Linag, H. M., Lai, C. C., Chiou, J. M., et al. (2011). Arabidopsis SUMO E3 ligase SIZ1 is involved in excess copper tolerance. Plant Physiol. 156, 2225-2234. doi: 10.1104/pp.111.178996

Cheng, M. C., Liao, P. M., Kuo, W. W., and Lin, T. P. (2013). The Arabidopsis ETHYLENE RESPONSE FACTOR1 regulates abiotic stress-responsive gene expression by binding to different cis-acting elements in response to different stress signals. Plant Physiol. 162, 1566-1582. doi: 10.1104/pp.113.221911

Chini, A., Fonseca, S., Fernandez, G., Adie, B., Chico, J. M., Lorenzo, O., et al. (2007). The JAZ family of repressors is the missing link in jasmonate signalling. Nature 448, 666-671. doi: 10.1038/nature06006

Colebrook, E. H., Thomas, S. G., Phillips, A. L., and Hedden, P. (2014). The role of gibberellin signalling in plant responses to abiotic stress. J. Exp. Biol. 217, 67-75. doi: 10.1242/jeb.089938

Conde, A., Chaves, M. M., and Gerós, H. (2011). Membrane transport, sensing and signaling in plant adaptation to environmental stress. Plant Cell Physiol. 52, 1583-1602. doi: 10.1093/pcp/pcr107

Conti, L., Nelis, S., Zhang, C., Woodcock, A., Swarup, R., Galbiati, M., et al. (2014). Small Ubiquitin-like modifier protein SUMO enables plants to control growth independently of the phytohormone gibberellin. Dev. Cell 28, 102-110. doi: 10.1016/j.devcel.2013.12.004

Craig Plett, D., and Møller, I. S. (2010). $\mathrm{Na}^{+}$transport in glycophytic plants: what we know and would like to know. Plant Cell Environ. 33, 612-626. doi: 10.1111/j.1365-3040.2009.02086.x

Creelman, R. A., and Mullet, J. E. (1995). Jasmonic acid distribution and action in plants: regulation during development and response to biotic and abiotic stress. Proc. Natl. Acad. Sci. U.S.A. 92, 4114-4119. doi: 10.1073/pnas.92.10.4114

DaCosta, M., and Huang, B. (2009). "Physiological adaptations of perennial grasses to drought stress," in Perspectives in Biophysical Plant Ecophysiology, eds E. De La Barrera and W. K. Smith (México: Universidad Nacional Autónoma de México), 169-190.

Daszkowska-Golec, A., and Szarejko, I. (2013). Open or close the gate-stomata action under the control of phytohormones in drought stress conditions. Front. Plant Sci. 4:138. doi: 10.3389/fpls.2013.00138

De Domenico, S., Bonsegna, S., Horres, R., Pastor, V., Taurino, M., Poltronieri, P., et al. (2012). Transcriptomic analysis of oxylipin biosynthesis genes 
and chemical profiling reveal an early induction of jasmonates in chickpea roots under drought stress. Plant Physiol. Biochem. 61, 115-122. doi: 10.1016/j.plaphy.2012.09.009

Dermastia, M., Ravnikar, M., Vilhar, B., and Kovač, M. (1994). Increased level of cytokinin ribosides in jasmonic acid-treated potato (Solanum tuberosum) stem node cultures. Physiol. Plant. 92, 241-246. doi: 10.1111/j.1399-3054.1994.tb05332.x

Dervinis, C., Frost, C. J., Lawrence, S. D., Novak, N. G., and Davis, J. M. (2010). Cytokinin primes plant responses to wounding and reduces insect performance. J. Plant Growth Regul. 29, 289-296. doi: 10.1007/s00344-009-9135-2

Divi, U. K., Rahman, T., and Krishna, P. (2010). Brassinosteroid-mediated stress tolerance in Arabidopsis shows interactions with abscisic acid, ethylene and salicylic acid pathways. BMC Plant Biol. 10:151. doi: 10.1186/1471-222910-151

Divi, U. K., Rahman, T., and Krishna, P. (2015). Gene expression and functional analyses in brassinosteroid-mediated stress tolerance. Plant Biotechnol. J. 151-164. doi: 10.1111/pbi.12396

Dobra, J., Motyka, V., Dobrev, P., Malbeck, J., Prasil, I. T., Haisel, D., et al. (2010). Comparison of hormonal response to heat, drought and combined stress in tobacco plants with elevated proline content. J. Plant Physiol. 167, 1360-1370. doi: 10.1016/j.jplph.2010.05.013

Du, H., Liu, H., and Xiong, L. (2013). Endogenous auxin and jasmonic acid levels are differentially modulated by abiotic stresses in rice. Front. Plant Sci. 4:397. doi: 10.3389/fpls.2013.00397

Dubiella, U., Seybold, H., Durian, G., Komander, E., Lassig, R., Witte, C. P., et al. (2013). Calcium-dependent protein kinase/NADPH oxidase activation circuit is required for rapid defense signal propagation. Proc. Natl. Acad. Sci. U.S.A. 110, 8744-8749. doi: 10.1073/pnas.1221294110

Evans, N. H. (2003). Modulation of guard cell plasma membrane potassium currents by methyl jasmonate. Plant Physiol. 131, 8-11. doi: 10.1104/pp.014266

FAO. (2005). Report of the Regional Workshop on Salt-Affected Soils From Sea Water Intrusion: Strategies for Rehabilitation and Management. Bangkok: FAO Regional Office of Asia and the Pacific.

FAO. (2013). Drought Report. FAO Land and Water. Available at: http://www.fao.org/docrep/017/aq191e/aq191e.pdf [accessed 22 June, 2015].

Fujita, M., Fujita, Y., Maruyama, K., Seki, M., Hiratsu, K., Ohme-Takagi, M., et al. (2004). A dehydration induced NAC protein, RD26, is involved in a novel ABAdependent stress-signaling pathway. Plant J. 39, 863-876. doi: 10.1111/j.1365313X.2004.02171.x

Fujita, M., Fujita, Y., Noutoshi, Y., Takahashi, F., Narusaka, Y., YamaguchiShinozaki, K., et al. (2006). Crosstalk between abiotic and biotic stress responses: a current view from the points of convergence in the stress signaling networks. Curr. Opin. Plant Biol. 9, 436-442. doi: 10.1016/j.pbi.2006.05.014

Gao, X. P., Wang, X. F., Lu, Y. F., Zhang, L. Y., Shen, Y. Y., Liang, Z., et al. (2004). Jasmonic acid is involved in the water-stress-induced betaine accumulation in pear leaves plant. Plant Cell Environ. 27, 497-507. doi: 10.1111/j.13653040.2004.01167.x

Gayatri, G., Agurla, S., and Raghavendra, A. S. (2013). Nitric oxide in guard cells as an important secondary messenger during stomatal closure. Front. Plant Sci. 4:425. doi: $10.3389 /$ fpls.2013.00425

Gehring, C. A., Irving, H. R., McConchie, R., and Parish, R. W. (1997). Jasmonates induce intracellular alkalinization and closure of Paphiopedilum guard cells. Ann. Bot. 80, 485-489. doi: 10.1006/anbo.1997.0471

Ghassemi, F., Jakeman, A. J., and Nix, H. A. (1995). Salinisation of Land and Water Resources. Canberra: University of New South Wales Press Ltd.

Gong, Z., Koiwa, H., Cushman, M. A., Ray, A., Bufford, D., Kore-eda, S., et al. (2001). Genes that are uniquely stress regulated in salt overly sensitive (sos) mutants. Plant Physiol. 126, 363-375. doi: 10.1104/pp.126.1.363

Gray, W. M. (2004). Hormonal regulation of plant growth and development. PLoS Biol. 2:e311. doi: 10.1371/journal.pbio.0020311

Harb, A., Krishnan, A., Ambavaram, M. M., and Pereira, A. (2010). Molecular and physiological analysis of drought stress in Arabidopsis reveals early responses leading to acclimation in plant growth. Plant Physiol. 154, 1254-1271. doi: 10.1104/pp.110.161752

Harms, K., Ramirez, I., and Penacortes, H. (1998). Inhibition of wound-induced accumulation of allene oxide synthase transcripts in flax leaves by aspirin and salicylic acid. Plant Physiol. 118, 1057-1065. doi: 10.1104/pp.118.3.1057

Haruta, M., Burch, H. L., Nelson, R. B., Barrett-Wilt, G., Kline, K. G., Mohsin, S. B., et al. (2010). Molecular characterization of mutant Arabidopsis plants with reduced plasma membrane proton pump activity. J. Biol. Chem. 285, 17918-17929. doi: 10.1074/jbc.M110.101733

Hasegawa, P. M., Bressan, R. A., Zhu, J. K., and Bohnert, H. J. (2000). Plant cellular and molecular responses to high salinity. Annu. Rev. Plant Physiol. Plant Mol. Biol. 51, 463-499. doi: 10.1146/annurev.arplant.51.1.463

Hazman, M., Hause, B., Eiche, E., Nick, P., and Riemann, M. (2015). Increased tolerance to salt stress in OPDA-deficient rice ALLENE OXIDE CYCLASE mutants is linked with an increased ROS-scavenging activity. J. Exp. Bot. 66, 3339-3352. doi: 10.1093/jxb/erv142

Heitz, T., Widemann, E., Lugan, R., Miesch, L., Ullmann, P., Désaubry, L., et al. (2012). Cytochromes P450 CYP94C1 and CYP94B3 catalyze two successive oxidation steps of plant hormone jasmonoyl-isoleucine for catabolic turnover. J. Biol. Chem. 287, 6296-6306. doi: 10.1074/jbc.M111.316364

Herde, O., Pena-Cortes, H., Willmitzer, L., and Eisahn, J. (1997). Stomatal responses to jasmonic acid, linolenic acid and abscisic acid in wild-type and ABAdeficient tomato plants. Plant Cell Environ. 20, 136-141. doi: 10.1046/j.13653040.1997.d01-11.x

Horváth, E., Szalai, G., and Janda, T. (2007). Induction of abiotic stress tolerance by salicylic acid signaling. J. Plant Growth Regul. 26, 290-300. doi: 10.1007/s00344007-9017-4

Hossain, M. A., Munemasa, S., Uraji, M., Nakamura, Y., Mori, I. C., and Murata, Y. (2011). Involvement of endogenous abscisic acid in methyl jasmonateinduced stomatal closure in Arabidopsis. Plant Physiol. 156, 430-438. doi: 10.1104/pp.111.172254

Hou, X., Lee, L. Y., Xia, K., Yan, Y., and Yu, H. (2010). DELLAs modulate jasmonate signaling via competitive binding to JAZs. Dev. Cell 19, 884-894. doi: 10.1016/j.devcel.2010.10.024

Huang, A. X., She, X. P., Cao, B., Zhang, B., Mu, J., and Zhang, S. J. (2009). Nitric oxide, actin reorganization and vacuoles change are involved in PEG 6000-induced stomatal closure in Vicia faba. Physiol. Plant. 136, 45-56. doi: 10.1111/j.1399-3054.2009.01212.x

Huang, D., Wu, W., Abrams, S. R., and Cutler, A. J. (2008). The relationship of drought-related gene expression in Arabidopsis thaliana to hormonal and environmental factors. J. Exp. Bot. 59, 2991-3007. doi: 10.1093/jxb/ern155

Ichimura, K., Mizoguchi, T., Yoshida, R., Yuasa, T., and Shinozaki, K. (2000). Various abiotic stresses rapidly activate Arabidopsis MAP kinases AtMPK4 and AtMPK6. Plant J. 24, 655-665. doi: 10.1046/j.1365-313x.2000. 00913.x

Ismail, A., Riemann, M., and Nick, P. (2012). The jasmonate pathway mediates salt tolerance in grapevines. J. Exp. Bot. 63, 2127-2139. doi: 10.1093/jxb/err426

Ismail, A., Seo, M., Takebayashi, Y., Kamiya, Y., Eiche, E., and Nick, P. (2014a). Salt adaptation requires efficient fine-tuning of jasmonate signaling. Protoplasma 251, 881-898. doi: 10.1007/s00709-013-0591-y

Ismail, A., Takeda, S., and Nick, P. (2014b). Life and death under salt stress: same players, different timing? J. Exp. Bot. 65, 2963-2979. doi: 10.1093/jxb/eru159

Jiang, Y., Liang, G., Yang, S., and Yu, D. (2014). Arabidopsis WRKY57 functions as a node of convergence for jasmonic acid-and auxin-mediated signaling in jasmonic acid-induced leaf senescence. Plant Cell 6, 230-245. doi: $10.1105 /$ tpc. 113.117838

Jung, H., Lee, D. K., Choi, Y. D., and Kim, J. K. (2015). OsIAA6, a member of the rice Aux/IAA gene family, is involved in drought tolerance and tiller outgrowth. Plant Sci. 236, 304-312. doi: 10.1016/j.plantsci.2015.04.018

Kang, D. J., Seo, Y. J., Lee, J. D., Ishii, R., Kim, K. U., Shin, D. H., et al. (2005). Jasmonic acid differentially affects growth, ion uptake and abscisic acid concentration in salt-tolerant and salt-sensitive rice cultivars. J. Agron. Crop Sci. 191, 273-282. doi: 10.1111/j.1439-037X.2005.00153.x

Kantar, M., Lucas, S. J., and Budak, H. (2011). Drought stress: molecular genetics and genomics approaches. Adv. Bot. Res. 57, 445-493. doi: 10.1016/B978-0-12387692-8.00013-8

Katou, S., Yoshioka, H., Kawakita, K., Rowland, O., Jones, J. D., Mori, H., et al. (2005). Involvement of PPS3 phosphorylated by elicitor-responsive mitogenactivated protein kinases in the regulation of plant cell death. Plant Physiol. 139, 1914-1926. doi: 10.1104/pp.105.066795

Kazan, K. (2015). Diverse roles of jasmonates and ethylene in abiotic stress tolerance. Trends Plant Sci. 20, 219-229. doi: 10.1016/j.tplants.2015.02.001

Kazan, K., and Manners, J. M. (2008). Jasmonate signaling: toward an integrated view. Plant Physiol. 146, 1459-1468. doi: 10.1104/pp.107.115717

Kazan, K., and Manners, J. M. (2013). MYC2: the master in action. Mol. Plant 6, 686-703. doi: $10.1093 / \mathrm{mp} / \mathrm{sss} 128$ 
Khan, S., and Stone, J. M. (2007). Arabidopsis thaliana GH3.9 in auxin and jasmonate cross talk. Plant Signal Behav. 2, 483-485. doi: 10.4161/psb.2.6.4498

Kim, E. H., Kim, Y. S., Park, S. H., Koo, Y. K., Choi, Y. D., Chung, Y. Y., et al. (2009). Methyl jasmonate reduces grain yield by mediating stress signals to alter spikelet development in rice. Plant Physiol. 149, 1751-1760. doi: 10.1104/pp.108.134684

Klay, I., Pirrello, J., Riahi, L., Bernadac, A., Cherif, A., Bouzayen, M., et al. (2014). Ethylene response factor SI-ERF.B.3 is responsive to abiotic stresses and mediates salt and cold stress response regulation in tomato. ScientificWorldJournal 2014, 167681. doi: $10.1155 / 2014 / 167681$

Knight, M. R., Campbell, A. K., Smith, S. M., and Trewavas, A. J. (1991). Transgenic plant aequorin reports the effects of touch and cold-shock and elicitors on cytoplasmic calcium. Nature 352, 524-526. doi: 10.1038/352524a0

Ko, J. H., Yang, S. H., and Han, K. H. (2006). Upregulation of an Arabidopsis RING$\mathrm{H} 2$ gene, XERICO, confers drought tolerance through increased abscisic acid biosynthesis. Plant J. 47, 343-355. doi: 10.1111/j.1365-313X.2006.02782.x

Kohli, A., Sreenivasulu, N., Lakshmanan, P., and Kumar, P. P. (2013). The phytohormone crosstalk paradigm takes center stage in understanding how plants respond to abiotic stresses. Plant Cell Rep. 32, 945-957. doi: 10.1007/s00299-013-1461-y

Kramell, R., Miersch, O., Atzorn, R., Parthier, B., and Wasternack, C. (2000). Octadecanoid derived alteration of gene expression and the "oxylipin signature" in stressed barley leaves. Implications for different signaling pathways. Plant Physiol. 123, 177-187. doi: 10.1104/pp.123.1.177

Kronzucker, H. J., Coskun, D., Schulze, L. M., Wong, J. R., and Britto, D. T. (2013). Sodium as nutrient and toxicant. Plant Soil 369, 1-23. doi: 10.1007/s11104-013$1801-2$

Kung, C. (2005). A possible unifying principle for mechanosensation. Nature 436, 647-654. doi: 10.1038/nature03896

Kurotani, K. I., Hayashi, K., Hatanaka, S., Toda, Y., Ogawa, D., Ichikawa, H., et al. (2015). Elevated levels of CYP94 family gene expression alleviate the jasmonate response and enhance salt tolerance in rice. Plant Cell Physiol. 56, 779-789. doi: $10.1093 / \mathrm{pcp} / \mathrm{pcv} 006$

Lee, J., Nam, J., Park, H. C., Na, G., Miura, K., Jin, J. B., et al. (2007). Salicylic acidmediated innate immunity in Arabidopsis is regulated by SIZ1 SUMO E3 ligase. Plant J. 49, 79-90. doi: 10.1111/j.1365-313X.2006.02947.x

Lee, T., Lur, H. S., Lin, V. H., and Chu, C. (1996). Physiological and biochemical changes related to methyl jasmonate-induced chilling tolerance of rice Oryza sativa L. Plant Cell Environ. 19, 65-74. doi: 10.1111/j.1365-3040.1996.tb00227.x

Lehmann, J., Atzorn, R., Brückner, C., Reinbothe, S., Leopold, J., Wasternack, C., et al. (1995). Accumulation of jasmonate, abscisic acid, specific transcripts and proteins in osmotically stressed barley leaf segments. Planta 197, 156-162. doi: 10.1007/BF00239952

Li, C., Fang, B., Yang, C., Shi, D., and Wang, D. (2009). Effects of various salt-alkaline mixed stresses on the state of mineral elements in nutrient solutions and the growth of alkali resistant halophyte Chloris virgata. J. Plant Nutr. 32, 1137-1147. doi: 10.1080/01904160902943163

Li, L., Van Staden, J., and Jager, A. K. (1998). Effects of plant growth regulators on the antioxidant system in seedlings of two maize cultivars subjected to water stress. Plant Growth Regul. 25, 81-87. doi: 10.1023/A:1010774725695

Lorenzo, O., Piqueras, R., Sánchez-Serrano, J. J., and Solano, R. (2003). ETHYLENE RESPONSE FACTOR1 integrates signals from ethylene and jasmonate pathways in plant defense. Plant Cell 15, 165-178. doi: 10.1105/tpc.007468

Lorenzo, O., and Solano, R. (2005). Molecular players regulating the jasmonate signalling network. Curr. Opin. Plant Biol. 8, 532-540. doi: 10.1016/j.pbi.2005.07.003

Mahmood, M., Bidabadi, S. S., Ghobadi, C., and Gray, D. J. (2012). Effect of methyl jasmonate treatments on alleviation of polyethylene glycol-mediated water stress in banana (Musa acuminata cv. 'Berangan', AAA) shoot tip cultures. Plant Growth Regul. 68, 161-169. doi: 10.1007/s10725-012-9702-6

McAinsh, M. R., and Hetherington, A. M. (1998). Encoding specificity in $\mathrm{Ca}^{2+}$ signalling systems. Trends Plant Sci. 3, 32-36. doi: 10.1016/S13601385(97)01150-3

Miller, G., Suzuki, N., Ciftci-Yilmaz, S., and Mittler, R. (2010). Reactive oxygen species homeostasis and signalling during drought and salinity stresses. Plant Cell Environ. 33, 453-467. doi: 10.1111/j.1365-3040.2009.02041.x

Mittler, R., and Blumwald, E. (2015). The roles of ROS and ABA in systemic acquired acclimation. Plant Cell 27, 64-70. doi: 10.1105/tpc.114.133090

Miura, K., and Tada, Y. (2014). Regulation of water, salinity, and cold stress responses by salicylic acid. Front. Plant Sci. 5:4. doi: 10.3389/fpls.2014.00004
Moons, A., Prinsen, E., Bauw, G., and Van Montagu, M. (1997). Antagonistic effects of abscisic acid and jasmonates on salt stress-inducible transcripts in rice roots. Plant Cell 9, 2243-2259. doi: 10.1105/tpc.9.12.2243

Munemasa, S., Oda, K., Watanabe-Sugimoto, M., Nakamura, Y., Shimoishi, Y., and Murata, Y. (2007). The coronatine-insensitive 1 mutation reveals the hormonal signaling interaction between abscisic acid and methyl jasmonate in Arabidopsis guard cells. Specific impairment of ion channel activation and second messenger production. Plant Physiol. 143, 1398-1407. doi: 10.1104/pp.106.091298

Munns, R. (2002). Comparative physiology of salt and water stress. Plant Cell Environ. 25, 239-250. doi: 10.1046/j.0016-8025.2001.00808.x

Munns, R., and Tester, M. (2008). Mechanisms of salinity tolerance. Annu. Rev. Plant Biol. 59, 651-668. doi: 10.1146/annurev.arplant.59.032607.092911

Nafie, E., Hathout, T., and Mokadem, A. S. A. (2011). Jasmonic acid elicits oxidative defense and detoxification systems in Cucumis melo L. cells. Braz. J. Plant Physiol. 23, 161-174. doi: 10.1590/S1677-04202011000200008

Naik, G. R., Mukherjee, I., and Reid, D. M. (2002). Influence of cytokinins on the methyl jasmonate-promoted senescence in Helianthus annuus cotyledons. Plant Growth Regul. 38, 61-68. doi: 10.1023/A:1020926902352

Nemhauser, J. L., Hong, F., and Chory, J. (2006). Different plant hormones regulate similar processes through largely nonoverlapping transcriptional responses. Cell 126, 467-475. doi: 10.1016/j.cell.2006.05.050

Nick, P. (2011). "Mechanics of the cytoskeleton," in Mechanical Integration of Plant Cells and Plants, ed. P. Wojtaszek (Berlin: Springer), 53-90. doi: 10.1007/978-3642-19091-9_3

Nishiyama, I. (1986). Lodging of rice plants and countermeasure. FFTC Book Ser. Taiwan 34, 152-163.

Pal, M., Szalai, G., Kovacs, V., Gondor, O. K., and Janda, T. (2013). "Salicylic acid-mediated abiotic stress tolerance. Salicylic Acid," in Plant Growth and Development, eds S. Hayat, A. Ahmed, and M. N. Alyemeni (Rotterdam: Springer), 183-247. doi: 10.1007/978-94-007-6428-6_10

Park, B. S., Song, J. T., and Seo, H. S. (2011). Arabidopsis nitrate reductase activity is stimulated by the E3 SUMO ligase AtSIZ1. Nat. Commun. 2, 400. doi: $10.1038 /$ ncomms1408

Passioura, J. B. (2002). Environmental biology and crop improvement. Funct. Plant Biol. 29, 537-546. doi: 10.1071/FP02020

Pedranzani, H., Sierra-de-Grado, R., Vigliocco, A., Miersch, O., and Abdala, G. (2007). Cold and water stresses produce changes in endogenous jasmonates in two population of Pinus pinaster Ait. Plant Growth Regul. 52, 111-116. doi: 10.1007/s10725-007-9166-2

Peng, J., Richards, D. E., Hartley, N. M., Murphy, G. P., Devos, K. M., Flintham, J. E., et al. (1999). Green revolution genes encode mutant gibberellin response modulators. Nature 400, 256-261. doi: 10.1038/22307

Peng, Z., Han, C., Yuan, L., Zhang, K., Huang, H., and Ren, C. (2011). Brassinosteroid enhances jasmonate-induced anthocyanin accumulation in Arabidopsis seedlings. J. Integr. Plant Biol. 53, 632-640. doi: 10.1111/j.17447909.2011.01042.x

Perales, L., Arbona, B., Gómez-Cadenas, A., Cornejo, M. J., and Sanz, A. (2005). A relationship between tolerance to dehydration of rice lines and ability for ABA synthesis under stress. Plant Physiol. Biochem. 43, 786-792. doi: 10.1016/j.plaphy.2005.07.002

Pessarakli, M. (2001). Handbook of Plant and Crop Physiology, 2nd Edn. New York: Marcel Dekker Inc., 520-530. doi: 10.1201/9780203908426

Pinheiro, C., and Chaves, M. M. (2011). Photosynthesis and drought: can we make metabolic connections from available data? J. Exp. Bot. 62, 869-882. doi: $10.1093 /$ jxb/erq340

Poltronieri, P., Taurino, M., Domenico, S. D., Bonsegna, S., and Santino, A. (2013). "Activation of the jasmonate biosynthetic pathway in roots in drought stress" in Climate Change and Abiotic Stress Tolerance, eds N. Tuteja and S.S. Gill (Weinheim: Wiley-VCH Verlag GmbH), 325-342. doi: 10.1002/9783527675265.ch13

Proietti, S., Bertini, L., Timperio, A. M., Zolla, L., Caporale, C., and Caruso, C. (2013). Crosstalk between salicylic acid and jasmonate in Arabidopsis investigated by an integrated proteomic and transcriptomic approach. Mol. Biosyst. 9, 1169-1187. doi: 10.1039/c3mb25569g

Qi, T., Song, S., Ren, Q., Wu, D., Huang, H., Chen, Y., et al. (2011). The Jasmonate-ZIM-domain proteins interact with the WD-Repeat/bHLH/MYB complexes to regulate Jasmonate-mediated anthocyanin accumulation and trichome initiation in Arabidopsis thaliana. Plant Cell 23, 1795-1814. doi: $10.1105 /$ tpc. 111.083261 
Rao, P. S., Mishra, B., Gupta, S. R., and Rathore, A. (2008). Reproductive stage tolerance to salinity and alkalinity stresses in rice genotypes. Plant Breed. 127, 256-261. doi: 10.1111/j.1439-0523.2007.01455.x

Raorane, M. L., Mutte, S. M., Varadarajan, A. R., Pabuayon, I. M., and Kohli, A. (2013). Protein SUMOylation and plant abiotic stress signaling: in silico case study of rice RLKs, heat-shock and $\mathrm{Ca}^{2+}$-binding proteins. Plant Cell Rep. 32, 1053-1065. doi: 10.1007/s00299-013-1452-Z

Rassaa, N., Ben Haj Salah, H., and Latiri, K. (2008). Thermal responses of Durum wheat Triticum durum to early water stress. Consequence on leaf and flower development. C. R. Biol. 331, 363-371. doi: 10.1016/j.crvi.2008.02.005

Reddy, A. R., Chaitanya, K. V., and Vivekanandan, M. (2004). Drought-induced responses of photosynthesis and antioxidant metabolism in higher plants. J. Plant Physiol. 161, 1189-1202. doi: 10.1016/j.jplph.2004.01.013

Ren, C., Han, C., Peng, W., Huang, Y., Peng, Z., Xiong, X., et al. (2009). A leaky mutation in DWARF4 reveals an antagonistic role of brassinosteroid in the inhibition of root growth by jasmonate in Arabidopsis. Plant Physiol. 151, 1412-1420. doi: 10.1104/pp.109.140202

Riera, M., Valon, C., Fenzi, F., Giraudat, J., and Leung, J. (2005). The genetics of adaptive responses to drought stress: abscisic acid-dependent and abscisic acid-independent signalling components. Physiol. Plant. 123, 111-119. doi: 10.1111/j.1399-3054.2005.00469.x

Roche, J., Hewezi, T., Bouniols, A., and Gentzbittel, L. (2009). Real-time PCR monitoring of signal transduction related genes involved in water stress tolerance mechanism of sunflower. Plant Physiol. Biochem. 47, 139-145. doi: 10.1016/j.plaphy.2008.10.007

Sánchez-Díaz, M., Tapia, C., and Antolín, M. C. (2008). Abscisic acid and drought response of Canarian laurel forest tree species growing under controlled conditions. Environ. Exp. Bot. 64, 155-161. doi: 10.1016/j.envexpbot.2008.05.011

Saniewski, M., Ueda, J., and Miyamoto, K. (2002). Relationships between jasmonates and auxin in regulation of some physiological processes in higher plants. Acta Physiol. Plant. 24, 211-220. doi: 10.1007/s11738-002-0013-9

Sano, H., Seo, S., Koizumi, N., Niki, T., Iwamura, H., and Ohashi, Y. (1996). Regulation of cytokinins of endogenous levels of jasmonic and salicylic acids in mechanically wounded tobacco plants. Plant Cell Physiol. 37, 762-769. doi: 10.1093/oxfordjournals.pcp.a029011

Savchenko, T., Kolla, A. V., Wang, C. Q., Nasafi, Z., Hicks, D. R., Phadungchob, B., et al. (2014). Functional convergence of oxylipin and abscisic acid pathways controls stomatal closure in response to drought. Plant Physiol. 164, 1151-1160. doi: $10.1104 /$ pp. 113.234310

Schachtman, D. P., Kumar, R., Schroeder, J. I., and Marsh, E. L. (1997). Molecular and functional characterization of a novel low-affinity cation transporter (LCT1) in higher plants. Proc. Natl. Acad. Sci. U.S.A. 94, 11079-11084. doi: 10.1073/pnas.94.20.11079

Schweighofer, A., Kazanaviciute, V., Scheikl, E., Teige, M., Doczi, R., Hirt, H., et al. (2007). The PP2C-type phosphatase AP2C1, which negatively regulates MPK4 and MPK6, modulates innate immunity, jasmonic acid, and ethylene levels in Arabidopsis. Plant Cell 19, 2213-2224. doi: 10.1105/tpc.106.049585

Seki, M., Umezawa, T., Urano, K., and Shinozaki, K. (2007). Regulatory metabolic networks in drought stress responses. Curr. Opin. Plant Biol. 10, 296-302. doi: 10.1016/j.pbi.2007.04.014

Seo, J. S., Joo, J., Kim, M. J., Kim, Y. K., Nahm, B. H., Song, S. I., et al. (2011). OsbHLH148, a basic helix-loop-helix protein, interacts with OsJAZ proteins in a jasmonate signaling pathway leading to drought tolerance in rice. Plant J. 65, 907-921. doi: 10.1111/j.1365-313X.2010.04477.x

Sharma, P., Jha, A. B., Dubey, R. S., and Pessarakli, M. (2012). Reactive oxygen species, oxidative damage, and antioxidant defense mechanisms in plants under stressful conditions. J. Bot. 2012, 217037. doi: 10.1155/2012/217037

Shi, H., Ishitani, M., Kim, C., and Zhu, J. K. (2000). The Arabidopsis thaliana salt tolerance gene SOS1 encodes a putative $\mathrm{Na}^{+} / \mathrm{H}^{+}$antiporter. Proc. Natl. Acad. Sci. U.S.A. 97, 6896-6901. doi: 10.1073/pnas.120170197

Shinozaki, K., and Yamaguchi-Shinozaki, K. (1997). Molecular responses to drought and cold stress. Curr. Opin. Biotechnol. 7, 161-167. doi: 10.1016/S09581669(96)80007-3

Shinozaki, K., and Yamaguchi-Shinozaki, K. (2000). Molecular responses to dehydration and low temperature: differences and cross-talk between two stress signaling pathways. Curr. Opin. Biotechnol. 3, 217-223. doi: 10.1016/S13695266(00)80068-0
Shinozaki, K., and Yamaguchi-Shinozaki, K. (2007). Gene networks involved in drought stress response and tolerance. J. Exp. Bot. 58, 221-227. doi: $10.1093 /$ jxb/erl164

Shyu, C., Figueroa, P., Depew, C. L., Cooke, T. F., Sheard, L. B., Moreno, J. E., et al. (2012). JAZ8 lacks a canonical degron and has an EAR motif that mediates transcriptional repression of jasmonate responses in Arabidopsis. Plant Cell 24, 536-550. doi: 10.1105/tpc.111.093005

Song, L. L., Ding, W., Shen, J., Zhang, Z. G., Bi, Y. R., and Zhang, L. X. (2008). Nitric oxide mediates abscisic acid induced thermotolerance in the calluses from two ecotypes of reed under heat stress. Plant Sci. 175, 826-832. doi: 10.1016/j.plantsci.2008.08.005

Sperdouli, I., and Moustakas, M. (2012). Interaction of proline, sugars, and anthocyanins during photosynthetic acclimation of Arabidopsis thaliana to drought stress. J. Plant Physiol. 169, 577-585. doi: 10.1016/j.jplph.2011.12.015

Sreenivasulu, N., Harshavardhan, V. T., Govind, G., Seiler, C., and Kohli, A. (2012). Contrapuntal role of ABA: does it mediate stress tolerance or plant growth retardation under long-term drought stress? Gene 506, 265-273. doi: 10.1016/j.gene.2012.06.076

Staswick, P. E., Serban, B., Rowe, M., Tiryaki, I., Maldonado, M. T., Maldonado, M. C., et al. (2005). Characterization of an Arabidopsis enzyme family that conjugates amino acids to indole-3-acetic acid. Plant Cell 17, 616-627. doi: $10.1105 /$ tpc. 104.026690

Stoynova-Bakalova, E., Petrov, P. I., Gigova, L., and Baskin, T. I. (2008). Differential effects of methyl jasmonate on growth and division of etiolated zucchini cotyledons. Plant Biol. 10, 476-484. doi: 10.1111/j.1438-8677.2008.00034.x

Su, Y. H., Liu, Y. B., and Zhang, X. S. (2011). Auxin-cytokinin interaction regulates meristem development. Mol Plant 4, 616-625. doi: 10.1093/mp/ssr007

Suhita, D., Kolla, V. A., Vavasseur, A., and Raghavendra, A. S. (2003). Different signaling pathways involved during the suppression of stomatal opening by methyl jasmonate or abscisic acid. Plant Sci. 164, 481-488. doi: 10.1016/S01689452(02)00432-6

Suhita, D., Raghavendra, A. S., Kwak, J. M., and Vavasseur, A. (2004). Cytoplasmic alkalization precedes reactive oxygen species production during methyl jasmonate- and abscisic acid-induced stomatal closure. Plant Physiol. 134, 1536-1545. doi: 10.1104/pp.103.032250

Svyatyna, K., and Riemann, M. (2012). Light-dependent regulation of the jasmonate pathway. Protoplasma 249, S137-S145. doi: 10.1007/s00709-012-0409-3

Takeuchi, K., Gyohda, A., Tominaga, M., Kawakatsu, M., Hatakeyama, A., Ishii, N., et al. (2011). RSOsPR10 expression in response to environmental stresses is regulated antagonistically by jasmonate/ethylene and salicylic acid signaling pathways in rice roots. Plant Cell Physiol. 52, 1686-1696. doi: $10.1093 / \mathrm{pcp} / \mathrm{pcr} 105$

Taki, N., Sasaki-Sekimoto, Y., Obayashi, T., Kikuta, A., Kobayashi, K., Ainai, T., et al. (2005). 12-oxo-phytodienoic acid triggers expression of a distinct set of genes and plays a role in wound-induced gene expression in Arabidopsis. Plant Physiol. 139, 1268-1283. doi: 10.1104/pp.105.067058

Thines, B., Katsir, L., Melotto, M., Niu, Y., Mandaokar, A., Liu, G., et al. (2007). JAZ repressor proteins are targets of the SCFCO1 complex during jasmonate signalling. Nature 448, 661-665. doi: 10.1038/nature05960

Tiryaki, I., and Staswick, P. E. (2002). An Arabidopsis mutant defective in jasmonate response is allelic to the auxin-signaling mutant axr1. Plant Physiol. 130, 887-894. doi: 10.1104/pp.005272

Tunnacliffe, A., and Wise, M. J. (2007). The continuing conundrum of the LEA proteins. Naturwissenschaften 94, 791-812. doi: 10.1007/s00114-007-0254-y

Wang, H., Wu, Z., Chen, Y., Yang, C., and Shi, D. (2011). Effects of salt and alkali stresses on growth and ion balance in rice (Oryza sativa L.). Plant Soil Environ. 57, 286-294.

Wang, J. W., Zheng, L. P., Wu, J. Y., and Tan, R. X. (2006). Involvement of nitric oxide in oxidative burst, phenylalanine ammonia-lyase activation and Taxol production induced by low-energy ultrasound in Taxus yunnanensis cell suspension cultures. Nitric Oxide 15, 351-358. doi: 10.1016/j.niox.2006.04.261

Wasternack, C. (2007). Jasmonates: an update on biosynthesis, signal transduction and action in plant stress response, growth and development. Ann. Bot. 100, 681-697. doi: 10.1093/aob/mcm079

Wasternack, C., and Hause, B. (2013). Jasmonates: biosynthesis, perception, signal transduction and action in plant stress response, growth and development. An update to the 2007 review in Annals of Botany. Ann. Bot. 111, 1021-1058. doi: $10.1093 / \mathrm{aob} / \mathrm{mct} 067$ 
Werner, T., Nehnevajova, E., Kollmer, I., Novak, O., Strnad, M., Kramer, U., et al. (2010). Root-specific reduction of cytokinin causes enhanced root growth, drought tolerance, and leaf mineral enrichment in Arabidopsis and tobacco. Plant Cell 22, 3905-3920. doi: 10.1105/tpc.109.072694

Wild, M., Davière, J. M., Cheminant, S., Regnault, T., Baumberger, N., Heintz, D., et al. (2012). The Arabidopsis DELLA RGA-LIKE3 is a direct target of MYC2 and modulates jasmonate signaling responses. Plant Cell 24, 3307-3319. doi: $10.1105 /$ tpc. 112.101428

Wilkinson, S., and Davies, W. J. (2010). Drought, ozone, ABA and ethylene: new insights from cell to plant to community. Plant Cell Environ. 33, 510-525. doi: 10.1111/j.1365-3040.2009.02052.x

Williams, W. D. (2001). Anthropogenic salinisation of inland waters. Hydrobiologia 466, 329-337. doi: 10.1023/A:1014598509028

Wu, H., Ye, H., Yao, R., Zhang, T., and Xiong, L. (2015). OsJAZ9 acts as a transcriptional regulator in jasmonate signaling and modulates salt stress tolerance in rice. Plant Sci. 232, 1-12. doi: 10.1016/j.plantsci.2014. 12.010

Xie, D. X., Feys, B. F., James, S., Nieto-Rostro, M., and Turner, J. G. (1998). COI1: an Arabidopsis gene required for jasmonate-regulated defense and fertility. Science 280, 1091-1094. doi: 10.1126/science.280.5366.1091

Xin, L., Wuliang, S., Shuqiu, Z., and Chenghou, L. (2005). Nitric oxide involved in signal transduction of jasmonic acid-induced stomatal closure of Vicia faba L. Chin. Sci. Bull. 50, 520-525. doi: 10.1360/982004-794

Xin, Z. Y., Zhou, X., and Pilet, P. E. (1997). Level changes of jasmonic, abscisic and indole-3yl acetic acids in maize under desiccation stress. J. Plant Physiol. 151, 120-124. doi: 10.1016/S0176-1617(97)80047-8

Xiong, L., and Yang, Y. (2003). Disease resistance and abiotic stress tolerance in rice are inversely modulated by an abscisic acid-inducible mitogen-activated protein kinase. Plant Cell 15, 745-759. doi: 10.1105/tpc.008714

Xiong, L. M., Schumaker, K. S., and Zhu, J. K. (2002). Cell signaling during cold, drought, and salt stress. Plant Cell Suppl. 2002, S165-S183.

Xoconostle-Cázares, B., Ramírez-Ortega, F. A., Flores-Elenes, L., and RuizMedrano, R. (2011). Drought tolerance in crop plants. Am. J. Plant Physiol. 5, 241-256.

Yamaguchi-Shinozaki, K., and Shinozaki, K. (2005). Organization of cis-acting regulatory elements in osmotic- and cold-stress-responsive promoters. Trends Plant Sci. 10, 88-94. doi: 10.1016/j.tplants.2004.12.012

Yamaguchi-Shinozaki, K., and Shinozaki, K. (2006). Transcriptional regulatory networks in cellular responses and tolerance to dehydration and cold stresses. Annu. Rev. Plant Biol. 57, 781-803. doi: 10.1146/annurev.arplant.57.032905.105444

Yeo, A. R. (1999). Predicting the interaction between the effect of salinity and climate change on crop plants. Sci. Hort. 78, 159-174. doi: 10.1016/S03044238(98)00193-9

Yoon, J. Y., Hamayun, M., Lee, S. K., and Lee, I. J. (2009). Methyl jasmonate alleviated salinity stress in soybean. J. Crop Sci. Biotechnol. 12, 63-68. doi: 10.1007/s12892-009-0060-5

Yordanov, I., Velikova, V., and Tsone, V. (2000). Plant response to drought, acclimation, and stress tolerance. Photosynthetica 30, 171-186. doi: 10.1023/A:1007201411474

Yuan, F., Yang, H., Xue, Y., Kong, D., Ye, R., Li, C., et al. (2014). OSCA1 mediates osmotic-stress-evoked $\mathrm{Ca}^{2+}$ increases vital for osmosensing in Arabidopsis. Nature 514, 367-371. doi: 10.1038/nature13593

Zentella, R., Zhang, Z. L., Park, M., Thomas, S. G., Endo, A., Murase, K., et al. (2007). Global analysis of DELLA direct targets in early gibberellin signaling in Arabidopsis. Plant Cell 19, 3037-3057. doi: 10.1105/tpc.107.054999

Zhang, A. Y., Zhang, J., Zhang, J. H., Ye, N. H., Zhang, H., Tan, M. P., et al. (2011). Nitric oxide mediates brassinosteroid-induced ABA biosynthesis involved in oxidative stress tolerance in maize leaves. Plant Cell Physiol. 52, 181-192. doi: $10.1093 / \mathrm{pcp} / \mathrm{pcq} 187$

Zhang, H., Huang, Z., Xie, B., Chen, Q., Tian, X., Zhang, X., et al. (2004). The ethylene-, jasmonate-, abscisic acid- and $\mathrm{NaCl}$-responsive tomato transcription factor JERF1 modulates expression of GCC box-containing genes and salt tolerance in tobacco. Planta 220, 262-270. doi: 10.1007/s00425-0041347-x

Zhu, J. K. (2007). Plant Salt Stress. Chichester: eLS. John Wiley \& Sons Ltd. doi: 10.1002/9780470015902.a0001300.pub2

Conflict of Interest Statement: The authors declare that the research was conducted in the absence of any commercial or financial relationships that could be construed as a potential conflict of interest.

Copyright (c) 2015 Riemann, Dhakarey, Hazman, Miro, Kohli and Nick. This is an open-access article distributed under the terms of the Creative Commons Attribution License (CC BY). The use, distribution or reproduction in other forums is permitted, provided the original author(s) or licensor are credited and that the original publication in this journal is cited, in accordance with accepted academic practice. No use, distribution or reproduction is permitted which does not comply with these terms. 